\title{
Reconstructing 800 years of summer temperatures in Scotland from tree rings
}

\author{
Miloš Rydval $^{1,2}$ (D) Neil J. Loader ${ }^{3} \cdot$ Björn E. Gunnarson $^{4} \cdot$ Daniel L. Druckenbrod $^{5}$ • \\ Hans W. Linderholm ${ }^{6} \cdot$ Steven G. Moreton $^{7} \cdot$ Cheryl V. Wood $^{1} \cdot$ Rob Wilson $^{1,8}$
}

Received: 28 April 2016/ Accepted: 29 November 2016 / Published online: 12 January 2017

(C) The Author(s) 2017. This article is published with open access at Springerlink.com

\begin{abstract}
This study presents a summer temperature reconstruction using Scots pine tree-ring chronologies for Scotland allowing the placement of current regional temperature changes in a longer-term context. 'Livingtree' chronologies were extended using 'subfossil' samples extracted from nearshore lake sediments resulting in a composite chronology $>800$ years in length. The North Cairngorms (NCAIRN) reconstruction was developed from a set of composite blue intensity high-pass and ring-width low-pass filtered chronologies with a range of detrending
\end{abstract}

Electronic supplementary material The online version of this article (doi:10.1007/s00382-016-3478-8) contains supplementary material, which is available to authorized users.

Miloš Rydval

rydval@gmail.com

1 School of Earth and Environmental Sciences, University of St Andrews, St Andrews, UK

2 Faculty of Forestry and Wood Sciences, Czech University of Life Sciences Prague, Kamýcká 129, Praha 6-Suchdol, 16521 Prague, Czech Republic

3 Department of Geography, Swansea University, Swansea, UK

4 Department of Physical Geography and Quaternary Geology, Stockholm University, Stockholm, Sweden

5 Department of Geological, Environmental, and Marine Sciences, Rider University, Lawrenceville, NJ, USA

6 Regional Climate Group, Department of Earth Sciences, University of Gothenburg, Gothenburg, Sweden

7 NERC Radiocarbon Facility (Environment), Scottish Enterprise Technology Park, Rankine Avenue, East Kilbride, Glasgow G75 0QF, UK

8 Lamont-Doherty Earth Observatory, Columbia University, Palisades, NY, USA and disturbance correction procedures. Calibration against July-August mean temperature explains $56.4 \%$ of the instrumental data variance over 1866-2009 and is well verified. Spatial correlations reveal strong coherence with temperatures over the British Isles, parts of western Europe, southern Scandinavia and northern parts of the Iberian Peninsula. NCAIRN suggests that the recent summer-time warming in Scotland is likely not unique when compared to multi-decadal warm periods observed in the $1300 \mathrm{~s}, 1500$ s, and 1730s, although trends before the mid-sixteenth century should be interpreted with some caution due to greater uncertainty. Prominent cold periods were identified from the sixteenth century until the early 1800 s—agreeing with the so-called Little Ice Age observed in other tree-ring reconstructions from Europe-with the 1690s identified as the coldest decade in the record. The reconstruction shows a significant cooling response 1 year following volcanic eruptions although this result is sensitive to the datasets used to identify such events. In fact, the extreme cold (and warm) years observed in NCAIRN appear more related to internal forcing of the summer North Atlantic Oscillation.

Keywords Temperature reconstruction - Subfossil - Treering $\cdot$ Scots pine $\cdot$ Scotland

\section{Introduction}

In the past few decades investigations aimed at understanding recent climate change have received considerable attention, focusing on the relationship of these changes to pre-industrial natural climatic variability and particularly on the role and extent of anthropogenic forcing (IPCC 2014). To gain insight into these broadscale changes, much attention has focussed on utilising 
palaeoclimatic proxy records to develop global (e.g. Mann and Jones 2003; Mann et al. 2008), but more commonly, northern hemispheric $(\mathrm{NH})$ scale reconstructions of temperature-a reflection of data availability (e.g. Briffa et al. 2001, 2002; Christiansen and Ljungqvist 2011; Cook et al. 2004; D'Arrigo et al. 2006; Esper et al. 2002; Hegerl et al. 2007; Jones et al. 1998; Moberg et al. 2005; Osborn and Briffa 2006; Schneider et al. 2015; Stoffel et al. 2015; Wilson et al. 2016).

Trees growing in climatically limiting environments are well known for their ability to record climatic conditions in the patterns of their tree rings (Fritts 1976). Tree-ring (TR) samples from environments where temperature predominantly limits growth have been used extensively to reconstruct past temperature at various locations around the world (Jones et al. 2009). These TR records have played an important role in the reconstruction and understanding of temperature at local and regional scales and long TR chronologies form vital components of annually resolved $\mathrm{NH}$ reconstructions of temperature (Wilson et al. 2016).

Despite the existence of a dense network of TR chronologies across Europe, the availability of long TR based temperature reconstructions still remains limited with only a handful of millennial (or near millennial) records existing at present. In Europe, TR based reconstructions of temperature have thus far been developed for northern Fennoscandia (e.g. Briffa et al. 1990, 1992; Esper et al. 2014; Grudd et al. 2002; Grudd 2008; Helama et al. 2002; McCarroll et al. 2013), central Sweden (e.g. Gunnarson et al. 2011; Linderholm and Gunnarson 2005; Zhang et al. 2015), the whole of Scandinavia (Linderholm et al. 2015), southern Finland (Helama et al. 2014), the European Alps (Büntgen et al. 2005, 2006), the Tatra Mts. (Büntgen et al. 2013), and the eastern Carpathians (Popa and Kern 2009). The development of additional long reconstructions in regions where records are short or do not exist is therefore vital in order to constrain estimates of past temperature variability by reducing spatial and temporal uncertainty and therefore expanding our understanding of climatic conditions during the late Holocene.

In Scotland, efforts similar to those cited above have been less advanced due to the difficulty of extending the relatively short living TR records (Wilson et al. 2012). Considering the location and close proximity of Scotland to the northeast Atlantic, tree growth from this region should reflect a strong influence of north Atlantic climate dynamics and potential sensitivity to modes of atmospheric variability such as the summer expression of the North Atlantic Oscillation (SNAO) (Linderholm et al. 2009). Also, considering the current absence of any other annually resolved near millennial temperature record from this region, the development of a long temperature reconstruction from this area would be of considerable value as it would fill an important spatial gap in the global mosaic of high resolution proxy archives.

Despite the very limited extent ( 1\%) of remaining semi-natural woodland in Scotland (Crone and Mills 2002), previous research has demonstrated that TR data can be used to reconstruct past temperatures. A summer temperature reconstruction (AD 1721-1975) was developed by Hughes et al. (1984) using ring-width (RW) and maximum latewood density (MXD) from living Scots pine (Pinus sylvestris L.) trees in the Scottish Highlands. However, no substantial update has been published since that time. Recently, Wilson et al. (2012) emphasised the potential for the development of a continuous millennial-length (or longer) TR based temperature reconstruction from Scots pine from the Cairngorms in central Scotland utilising subfossil wood preserved in Highland lakes. This paper presents the current status of this work.

The aim of this study is to build on the work of Hughes et al. (1984) and provide an extended and improved reconstruction of Scottish summer temperatures. Not only do we expand on the work of Hughes et al. (1984), both spatially and temporally, but we also utilise methodological improvements in chronology development to produce a more refined reconstruction. The expanded Scottish pine network has recently been investigated for its utility for spatial temperature reconstruction (Rydval et al. 2016b), and although valid estimates were derived for most Scottish locations, the study showed that the Cairngorms is the best region in Scotland from which a reconstruction of temperature can be developed. This is not only due to the strong temperature response of trees in that area and the availability of subfossil material preserved in Highland lakes which can be used to extend the living chronologies back in time (Wilson et al. 2012), but also due to the minimal disturbance impact from historical timber extraction. The influence of nonclimatic disturbance on the growth of Scots pine has been identified and recognised as a considerable challenge to reconstructing past temperatures using TR archives in Scotland. The impact of disturbance events on RW series was discussed and accounted for in Rydval et al. (2016a), where it was demonstrated that the influence of felling related disturbance could be identified in RW series and minimised to improve the climate signal expressed in RW chronologies which could subsequently be used to derive improved temperature reconstructions (Rydval et al. 2016b). This disturbance correction approach, based on Druckenbrod et al. (2013), is also applied here in the development of a temporally extensive temperature reconstruction.

This study presents an 800-year TR based reconstruction of summer temperatures for Scotland using ring width (RW) and blue intensity (BI, McCarroll et al. 2002; Rydval et al. 2014) data. The reconstruction is evaluated against other temperature records, including an independent 
reconstruction from central Scotland, long instrumental and reconstructed UK temperature records, and temperature reconstructions from around Europe. This new reconstruction extends the previously published Scottish dendroclimatic record (Hughes et al. 1984) by nearly 500 years and the combined utilisation of $\mathrm{BI}$ and RW data ensures the establishment of a strong climate-proxy relationship. This new record therefore represents an important contribution for furthering our understanding of past temperatures in this region and the climatic dynamics of the NW European sector as a whole.

\section{Methods}

\subsection{Study area}

The study area is located in the northern Cairngorm Mountains situated within the Cairngorms National Park in central Scotland (Fig. 1). Geologically, the Cairngorm Mountains plateau is formed by granitic intrusions with the highest peaks reaching elevations of around $1200 \mathrm{~m}$ a.s.l. and podzols representing the predominant soil type (Chapman et al. 2001). The relatively close proximity to the North Sea and the influence of the Gulf Stream results in a predominantly oceanic climate with mild summer and winter conditions (Dawson 2009).

\subsubsection{Sampled sites and data}

From a network of 44 Scots pine (Pinus sylvestris L.) sites across the Scottish Highlands, living tree chronologies (comprising 430 series/347 trees) from four sites in the Northern Cairngorms (including Loch an Eilein, Loch Gamnha, Green Loch and West Abernethy) were extended with 249 subfossil TR series (109 trees) collected from nearby lakes (Fig. 1). The four chronologies were not included in the spatial temperature reconstructions for Scotland (Rydval et al. 2016b), to ensure independent comparison and mutual validation between both reconstruction products.

To generate RW and BI measurements, samples from living pines were prepared, processed, cross-dated and measured according to the procedures described in Rydval et al. (2014). Subfossil samples (discs and cores) were surfaced with razor blades, chalk was applied to the surfaced sections to enhance visibility of ring boundaries, and RW was measured from wet samples using a traversing measuring stage. The subfossil samples were then air-dried and the discs were cut into smaller block laths along the previously measured radii using a bandsaw. Samples were then fully immersed in acetone for $72 \mathrm{~h}$ to extract any remaining resins from the wood. The samples were then dried, re-surfaced by sanding, scanned and RW and BI measured following the steps outlined in Rydval et al. (2014).
Fig. 1 Location of the Cairngorms National Park and sampled sites. (Sites included in the North Cairngorms reconstruction (NCAIRN) are highlighted in yellow)

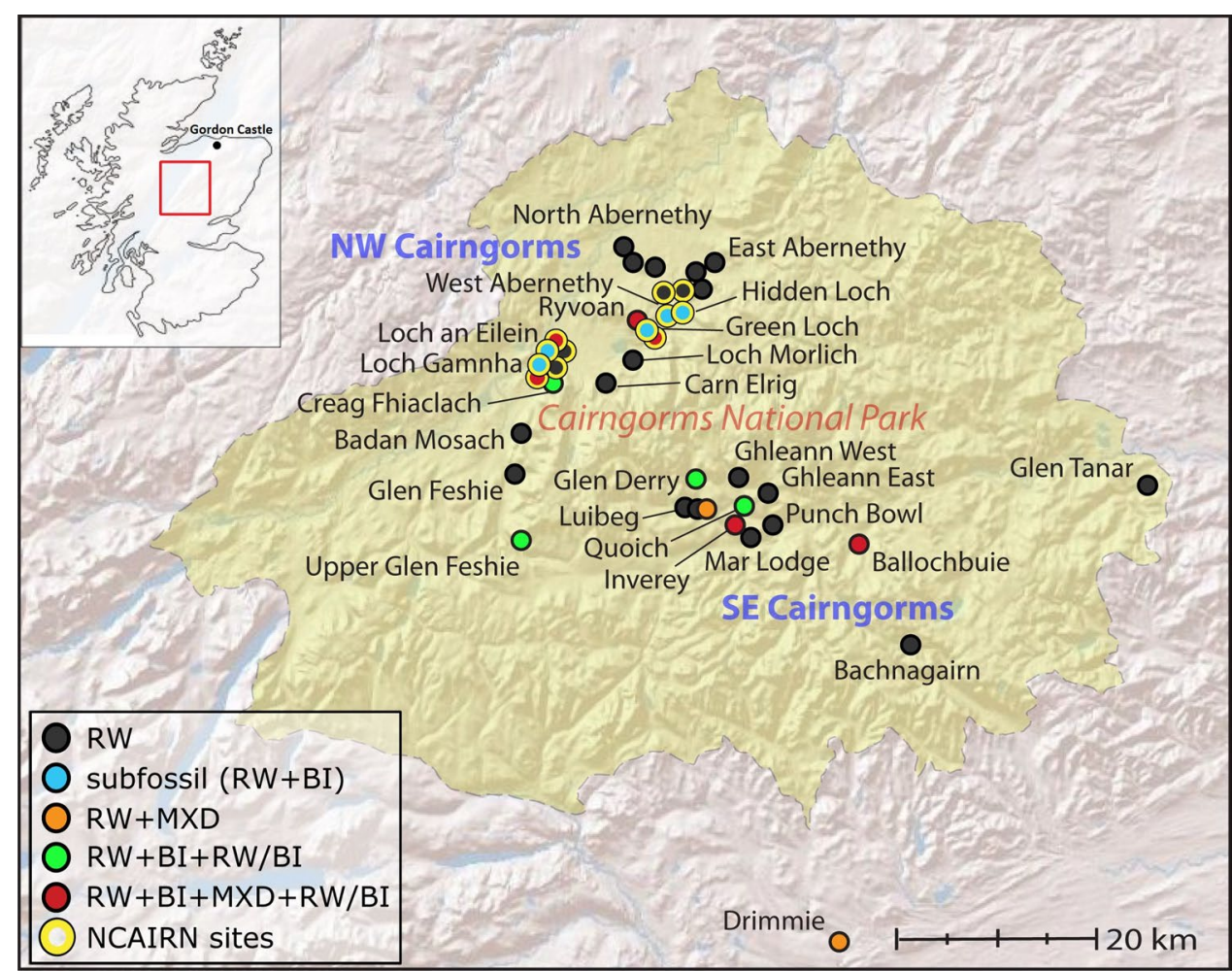


Verification of relative dating consistency was performed by comparing the 'wet' and 'dry' (i.e. samples measured before and after drying) RW measurements. Independent crossdating of RW and BI series was performed using COFECHA (Grissino-Mayer 2001) and CDendro (Larsson 2014), and dating agreement using both TR variables was interpreted as validation of the correct calendar dating of samples. In addition to crossdating validation of subfossil series using both RW and BI data, radiocarbon $\left({ }^{14} \mathrm{C}\right)$ dating of select samples was also performed (Fig. 2).

\subsection{Climate data}

The target data for this reconstruction was the July-August mean temperature dataset for mainland Scotland (SMT, Jones and Lister 2004), used back to 1866. This series was extended to 2009 with the CRU TS3.10 mean monthly $\left(0.5^{\circ}\right)$ gridded temperature data $\left(57.25^{\circ} \mathrm{N}, 3.75^{\circ} \mathrm{W}\right.$-Harris et al. 2014$)$ by scaling the gridded data to the SMT dataset based on the 1901-2004 common period of overlap to produce an extended SMT (ESMT) record.

\subsection{Chronology development}

Considering the relatively close proximity of the sites, the living-tree and subfossil data for all four locations were combined into one single dataset to maximise the common signal and minimise noise. The Expressed Population Signal (EPS - Wigley et al. 1984), a metric frequently used to express the degree to which a TR chronology reflects a hypothetical perfect population chronology, was used to assess signal strength. An overview of RW and BI replication and EPS of the living and subfossil series is presented in Fig. 2 (see Supplementary Figure S1 for full chronology replication and temporal span of individual samples). The period 1200-2010 was used for the reconstruction as replication was $>10$ series.

\subsubsection{RW detrending}

A range of RW chronology detrending options were applied to both the living and subfossil data. Düthorn et al. (2013, 2015) and Linderholm et al. (2014) discussed the possible introduction of biases when attempting to reconstruct past climatic conditions from living and subfossil samples which are not from the same immediate area where trees may have experienced differing micro-site conditions
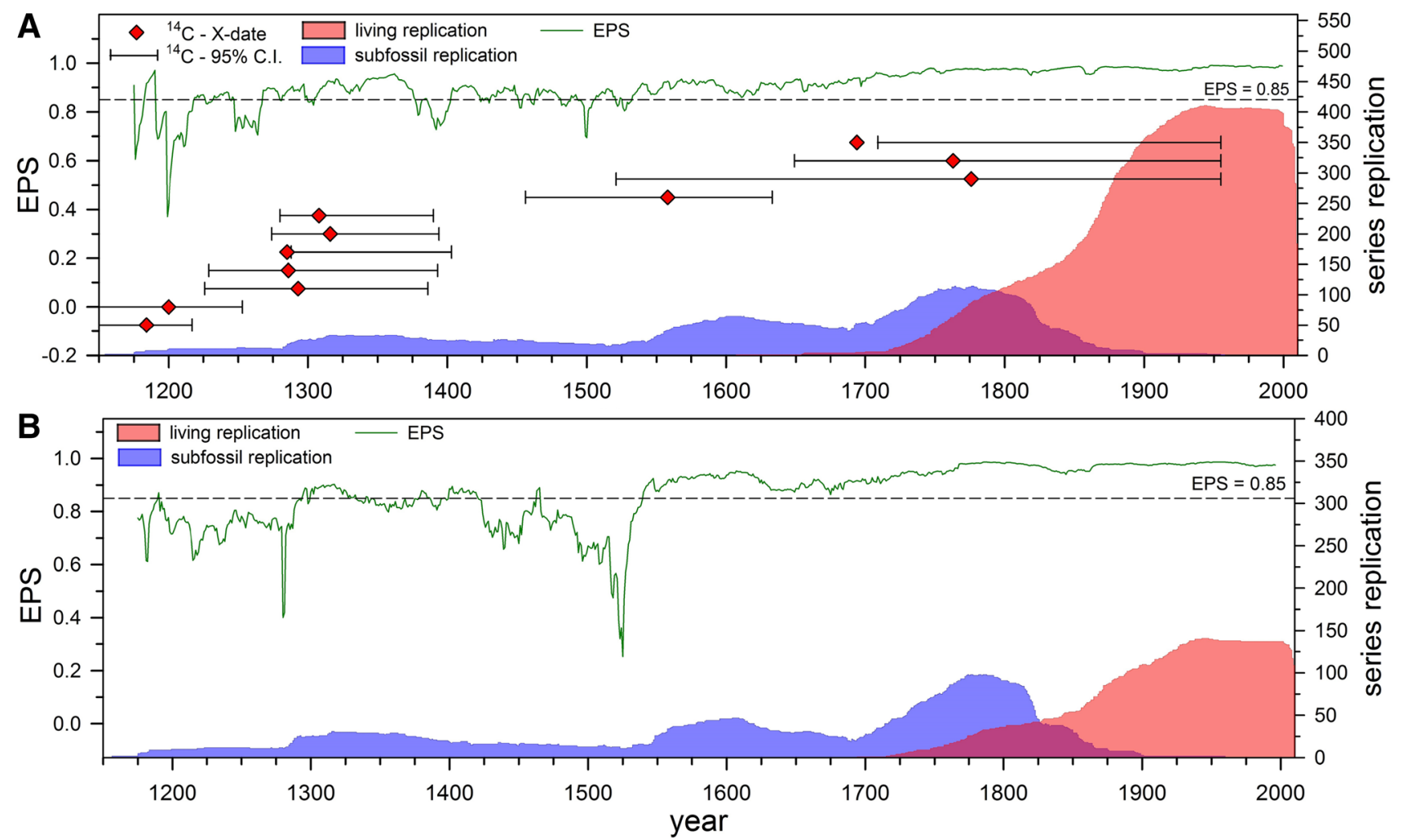

Fig. 2 a RW and b BI living and subfossil sample replication with EPS for the combined chronologies (EPS in $\mathbf{b}$ is shown for the high frequency component of $\mathrm{BI})$. The $95 \%$ confidence range of ${ }^{14} \mathrm{C}$-dated samples and the actual $\mathrm{RW}$ and $\mathrm{BI}$ cross-date are also included in a 
(i.e. at a lakeside vs. some distance away from the shore). Since many of the living samples were not obtained from the immediate shoreline and the exact origin of subfossil samples could also not be determined (i.e. transportation of some samples to the lakes may have resulted from logging activities in areas proximal to the lakes), the data from living and subfossil samples were detrended separately before pooling for the final composite. Further, significant impacts related to historical tree felling that potentially impart trend bias in the data need to be first minimised before detrending (Rydval et al. 2016a). Taking into account different disturbance correction approaches and detrending options, multiple chronology options were utilised for the final reconstruction to derive a detrending uncertainty term.

\subsubsection{Curve intervention detection variants}

The presence of disturbance-related growth release 'trends' resulting from centuries of woodland exploitation in Scotland, which can weaken the climate signal by obscuring mid-to-low frequency climate related information in the RW chronologies, was extensively discussed in Rydval et al. (2016a). Although such effects were found to be minimal in the Cairngorms as a whole, significant disturbance signals were noted for the living trees at the Loch Gamnha site. Originally based on the method of Druckenbrod (2005) and Druckenbrod et al. (2013), the same overall approach for disturbance identification and correction, involving the curve intervention detection (CID) method as utilised in Rydval et al. (2016a), was employed here. In this time-series intervention detection procedure, a value of $1 \mathrm{~mm}$ is added to each measurement to avoid potential loss of RW information before undertaking CID disturbance identification and correction. RW measurements are first power transformed (Cook and Peters 1997) followed by negative exponential or linear detrending. Outliers from distributions of 9-30 year running means based on residuals of individual detrended series and AR model estimates are used to identify disturbance-related growth releases. Each identified growth release trend is removed by fitting a curve (Warren 1980). As the presence of low frequency disturbance related biases would weaken the climate signal in the data, only disturbance corrected (post-CID) versions were used to reconstruct temperature as the corrected versions were on the whole found to produce considerably stronger calibrations than the uncorrected versions (Rydval et al. 2016a).

Two disturbance correction chronology versions were developed. The first of these disturbance correction variants, introduced and applied in Rydval et al. (2016a) and briefly described above, is hereafter referred to as CID-v1. The second disturbance correction variant is an updated version and is referred to as CID-v2. The primary difference between the two versions is that CID-v2 applies a minor modification in the disturbance detection algorithm by performing autoregressive modelling on series with a mean of 'zero' instead of 'unity'. While the former facilitates more effective fitting of the Warren curve (Warren 1980) to the disturbance-related growth trends, a more conventional approach is to apply autoregressive modelling to a zero-mean series as incorporated in CID-v2.

\subsubsection{RW Detrending variants}

The living RW data (CID-v1+v2) were detrended using the signal free (SF) approach (Melvin and Briffa 2008) by fitting either a negative exponential or linear function of negative or zero slope and calculating indices by division. As temperatures for the last 300 years trended from cooler LIA conditions until the warmth of the twentieth/twentyfirst century (Rydval et al. 2016b), no gain was identified for the living data by the utilisation of the relatively noisy regional curve standardisation approach (RCS-Briffa and Melvin 2011; Briffa et al. 1992) which allows the retention of low frequency information at time-scales greater than the mean length of the samples.

For the subfossil RW data, as with the living data, a standard negative exponential or linear regression (with SF) approach using CID-v1 + v2 versions of the RW data was also used to derive two variants. Further, RCS was also utilised as standard detrending approaches might remove warm to cool period decreasing trends because conventional data adaptive detrending approaches restrict the amount of extractable low frequency information (Cook et al. 1995). RCS attempts to address this issue by developing a single empirically derived 'regional' detrending curve for all series and has been used extensively in dendroclimatological studies to extract low frequency signals (e.g. Anchukaitis et al. 2013; Briffa et al. 1992; Büntgen et al. 2005; D’Arrigo et al. 2006; Esper et al. 2002; Wilson et al. 2005). RCS was performed by splitting the subfossil series into two equal groups of high and low growth rates based on the mean growth rate of the first 50 years (a shorter period was used in a few exceptional cases where samples had $<50$ rings). Separate mean RCS curves were used for each group, detrended independently and the resultant indices averaged together. Pith offset (PO) estimates were used to help limit distortion of each regional curve (Briffa and Melvin 2011). For a small minority of samples ( 3\%) the PO was either unknown or could not be estimated. In such cases $\mathrm{PO}$ was assigned a zero value.

For all variants, the indices of the individual subfossil series were scaled to the living-tree chronology according to the relative difference in mean and variance of the subfossil and living chronologies over their common well replicated period of overlap (1720-1897-EPS >0.85). 
Following this subfossil re-scaling, the living and subfossil indices were averaged to produce a single RW chronology and the variance stabilised using a 51-year window (Osborn et al. 1997).

Overall, a total of two living tree (SF+CID-v1 and $\mathrm{SF}+\mathrm{CID}-\mathrm{v} 2)$ and four subfossil (SF+CID-v1, SF + CIDv2， SF-RCS + CID-v1， SF-RCS + CID-v2) chronology variants were developed. Each of the living-tree chronology variants was combined as described above with the SF and SF-RCS subfossil variants of the same CID version (i.e. not mixing different CID versions between living and subfossil data) to produce four RW chronology variants. These different iterations allow an estimate of the detrending uncertainty.

\subsubsection{BI detrending}

Living and subfossil BI series were detrended separately by fitting linear regression functions after inversion of the series (Rydval et al. 2014) and the indices were calculated by subtraction. As with RW, the indices of individual subfossil BI series were then scaled to the living data according to their common well replicated 1720-1897 period of overlap. The individual indices of the living and re-scaled subfossil series were then combined into a single chronology and a 51-year window was used to stabilise the chronology variance (Osborn et al. 1997). Although recent research has demonstrated that it is possible to correct for potential low frequency biases in BI (Björklund et al. 2014a, b) when applied to subfossil 'drywood', it remains unclear whether a similar procedure can be applied to 'wet' subfossil wood, which was used in this study, since material preserved in this way may be affected by additional discolouration issues leading to as yet unidentified biases (Björklund et al. 2014b). For this reason, development of a BI only reconstruction was not performed.

\subsection{Composite BI and RW chronologies}

Rydval et al. (2016b) detailed the relatively weak temperature response of Scottish RW data at high frequencies, while also observing a limited expression of low frequency trends in the BI data. Utilising these TR variables at frequencies where they expressed strong coherence with summer temperatures (i.e. low frequency for RW and high frequency for $\mathrm{BI}$ ) resulted in superior calibration over more traditional approaches. After detrending, composite versions of the full-length BI and RW chronologies were produced by combining the high frequency (highpass) BI and low frequency (lowpass) RW components according to the procedure described in Rydval et al. (2016b). Despite some differences in parameter specific response, July-August mean temperatures were selected as the optimal compromise climatic season since both BI and RW exhibit the strongest response to the summer months (correlation response function analysis of the RW, BI and composite chronologies with instrumental temperature data is presented in Supplementary Figure S2) and this is also in accordance with previous studies in this region (e.g. Hughes et al. 1984; Rydval et al. 2016b; Wilson et al. 2012). A frequency cut-off of 18 years was determined by the intersection of decreasing coherency strength between BI and RW with instrumental July-August temperature data and applied for the highpass/ lowpass filtering procedure (see Supplementary Figure S3). After filtering, the high-pass (low-pass) BI (RW) series were scaled (Esper et al. 2005) to the instrumental data, filtered in the same way, and thereafter the scaled RW and BI series were combined by addition into a single time-series and rescaled to the original (unfiltered) instrumental temperature series.

\subsection{Calibration and verification}

The skill of each reconstruction variant was assessed by performing a set of regression-based calibration and verification procedures. The period from 1901 to 2009 was split into calibration (1901-1954) and verification (1955-2009) periods. The assessment was repeated by reversing the two periods. A final full 1901-2009 period calibration was undertaken and the period from 1866 to 1900 retained for an independent assessment of the full calibration. A range of calibration and verification statistics, including the $\mathrm{r}^{2}$ for the calibration and verification periods, the coefficient of efficiency (CE) and the root-mean-square error (RMSE), were calculated. A final regression-based reconstruction was developed as a weighted mean (weighted according to the RMSE over the 1866-1900 independent verification period) of all four reconstruction variants covering $\mathrm{AD}$ 1200-2010.

Reconstruction uncertainty was determined firstly by calculating the 2 sigma standard error of the estimate from the regression for each of the four individual reconstructions based on the 1901-2009 period calibration. The full range between these four error estimates was used to derive the confidence interval for the final reconstruction. Although this is a rather conservative assessment of the error range, it attempts to take into account periods of individual reconstruction agreement and disagreement by combining detrending error with calibration uncertainty (Esper et al. 2007).

\subsection{Superposed epoch analysis}

Recent discussions have highlighted a need to develop more detailed assessments of the regional response and sensitivity of temperature sensitive TR records to volcanic 
forcing (e.g. Anchukaitis et al. 2012; D'Arrigo et al. 2013; Esper et al. 2013; Mann et al. 2012). As no evaluation of Scottish TR data to volcanic forcing has previously been undertaken, we explore it herein. Superposed epoch analysis (SEA) of selected volcanic events presented in Sigl et al. (2015) (hereafter SIGL) and an older set of events identified from the Gao et al. (2008) index (hereafter GAO) was undertaken. For each set of events, SEA was performed by aligning sections of reconstructed temperature estimates for multiple volcanic events according to the year of detection in the ice core record. The SIGL list was compiled by selecting events with volcanic sulphate deposition $>15 \mathrm{~kg} \mathrm{~km}^{-2}$ in the Greenland ice core records and the GAO list included $\mathrm{NH}$ sulphate aerosol injection events $>15 \mathrm{Tg}$. For the analysis, 10 years before and after the event were examined. The series were expressed as anomalies relative to the 10 -year period prior to the event. All instances were averaged to determine a mean response to the events and the $95 \%$ significance threshold was determined using a block resampling bootstrap technique (Adams et al. 2003; Blarquez and Carcaillet 2010).

\section{Results and discussion}

\subsection{North Cairngorms reconstruction}

EPS values $>0.85$, coinciding with high replication in the RW and BI data, are evident back to the mid-1500s (Fig. 2). With generally lower replication before the mid-sixteenth century, EPS for the RW data (Fig. 2a) nevertheless generally remains reasonably high with a few weaker periods around 1400 and 1500 and in particular before $\sim 1280$ when replication decreases and EPS drops more noticeably below the commonly used threshold. The BI chronology replication and signal strength (Fig. 2b) generally mirror the RW results with the exception of an additional weak period around 1425-1550 (a particularly weakly replicated period comprising relatively short samples). Although reconstructions are generically deemed reliable when EPS is $>0.85$, here the pre $\sim 1550$ period, where replication is $>10$ series, is used to allow extension of the reconstruction further back in time- but with caveats of decreased confidence for these earlier periods. The full period of the presented reconstruction is $1200-2010$.

Examining the four individual BI-high-pass/RW-lowpass composite chronologies presented in Fig. 3, the two RCS-SF chronologies, as expected, express more low frequency variance than their SF-only counterparts. Increased spread among the chronologies is apparent before $\sim 1740$ and is most evident in the period around 1300 and from the late 1500 s until $\sim 1700$. The period $1280-1300$ also appears as a distinct episode of peak tree establishment which might suggest a slight juvenile growth rate bias at this time.

Table 1 details the calibration and verification statistics for each of the four time-series variants. Each series portrays a similar level of reconstruction skill as expressed by the calibration $\left(\mathrm{r}^{2}{ }_{(1901-2009)}=0.54-0.56\right)$ and verification $\left(r^{2}{ }_{(1866-1900)}=0.54-0.57\right)$ results. However, the similarity of the results is partly a reflection of the limited length of instrumental data which restricts reconstruction assessment to the period covered predominantly by living-tree data (and hence why detrending uncertainty was included in estimation of the reconstruction error range). Nevertheless, a visual assessment of the chronologies in Fig. 3b suggests a high degree of similarity among the chronology variants back to $\sim 1750$. Figure 4 presents the instrumental record together with the final calibrated North Cairngorms reconstruction, which was derived by averaging the four variants and weighting them using the validation period RMSE (Table 1). Good agreement is observed between observed and reconstructed temperatures during the 1901-2009 full calibration period $\left(\mathrm{r}^{2}=0.57\right)$ as well as over the $1866-1900$ independent verification period $\left(\mathrm{r}^{2}=0.56\right)$.

The final North Cairngorms (NCAIRN) reconstruction is presented in Fig. 5 and the warmest and coldest reconstructed years and decades summarised in Table 2. Importantly, although the range of uncertainty is small over the instrumental period and generally also back to the mid1700 s, before that time there is a wider spread in the confidence limits with variations in the error range reflecting periods of greater and lesser agreement among the individual chronology variants (Fig. 3). In general, however, the reconstruction captures well the late twentieth and early twenty-first century warming (Fig. 4). Considering the range of uncertainty, the recent warming is not unique with 2001-2010 representing the third warmest decade in the record (Table 2). Other notably warm reconstructed periods include two shorter periods (1280-1290 and 1300-1320) in the early part of the record, suggesting the possibility of previous warmer conditions during the late Medieval. Other warm decadal periods, similar to the present, are 1490-1510, 1370-1380 and 1730-1740. Despite containing two of the warmest decades (Table 2), the interval around 1300 is associated with considerable uncertainty and reduced replication. Furthermore, representation of this period in the RCS reconstruction versions may potentially be biased by a concentrated period of recruitment around 1300. However, historical records indicate that the 1280 s were marked by climatically favourable conditions with hot, dry summers, though the early 1300 s were characterised by deteriorating climate with poor harvests, famine and wet conditions (Dawson 2009; Lamb 1964). It is therefore not clear to what extent this reconstructed early 

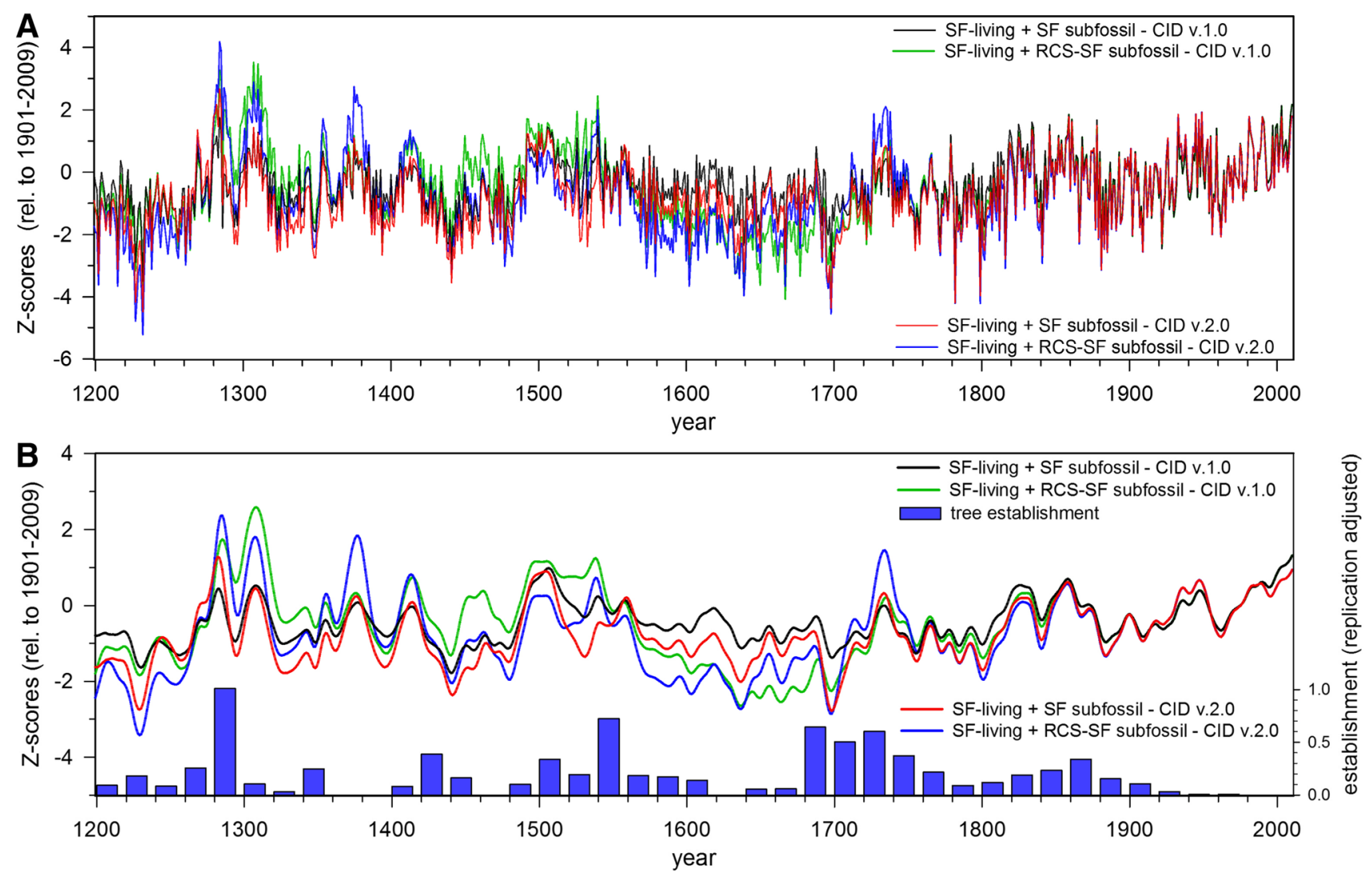

Fig. 3 Four versions of composite (BI + RW) chronologies a untransformed and b smoothed with a 20-year low-pass Gaussian filter. Chronologies are expressed as Z-scores relative to the 1901-2009 period. Tree establishment represents the number of established dates (using pith estimates) in 20 year blocks divided by the mean replication in each respective period. (Note that because the pairs of CID v1.0 and CID v2.0 chronologies are virtually identical after $\sim 1850$, the figure appears to show only two chronologies after that time)
Table 1 Calibration and verification statistics of the individual reconstructions

\begin{tabular}{|c|c|c|c|c|}
\hline & $\mathrm{SF}-\mathrm{CID}$ v1 & $\begin{array}{l}\text { SF + } 2 \text { RCS-SF } \\
\text { CID v1 }\end{array}$ & $\mathrm{SF}-\mathrm{CID}$ v2 & $\begin{array}{l}\mathrm{SF}+2 \\
\mathrm{RCS}-\mathrm{SF} \\
\mathrm{CID} \text { v2 }\end{array}$ \\
\hline \multicolumn{5}{|l|}{ 1901-1954 Calibration } \\
\hline Calibration $\mathrm{r}^{2}$ & 0.55 & 0.56 & 0.59 & 0.59 \\
\hline Verification $r^{2}(1955-2009)$ & 0.53 & 0.53 & 0.50 & 0.50 \\
\hline Verification CE & 0.52 & 0.52 & 0.43 & 0.43 \\
\hline \multicolumn{5}{|l|}{ 1955-2009 Calibration } \\
\hline Calibration $\mathrm{r}^{2}$ & 0.53 & 0.53 & 0.50 & 0.50 \\
\hline Verification $r^{2}(1901-1954)$ & 0.55 & 0.56 & 0.59 & 0.59 \\
\hline Verification CE & 0.55 & 0.55 & 0.51 & 0.50 \\
\hline \multicolumn{5}{|l|}{ 1901-2009 Calibration } \\
\hline Calibration $r^{2}$ & 0.56 & 0.56 & 0.54 & 0.54 \\
\hline Mean CE & 0.54 & 0.54 & 0.47 & 0.47 \\
\hline Regression standard error & 0.60 & 0.60 & 0.61 & 0.61 \\
\hline \multicolumn{5}{|c|}{ 1866-1900 Independent verification } \\
\hline Verification $\mathrm{r}^{2}$ & 0.57 & 0.57 & 0.55 & 0.54 \\
\hline Verification CE & 0.55 & 0.55 & 0.50 & 0.49 \\
\hline RMSE & 0.54 & 0.54 & 0.57 & 0.57 \\
\hline
\end{tabular}




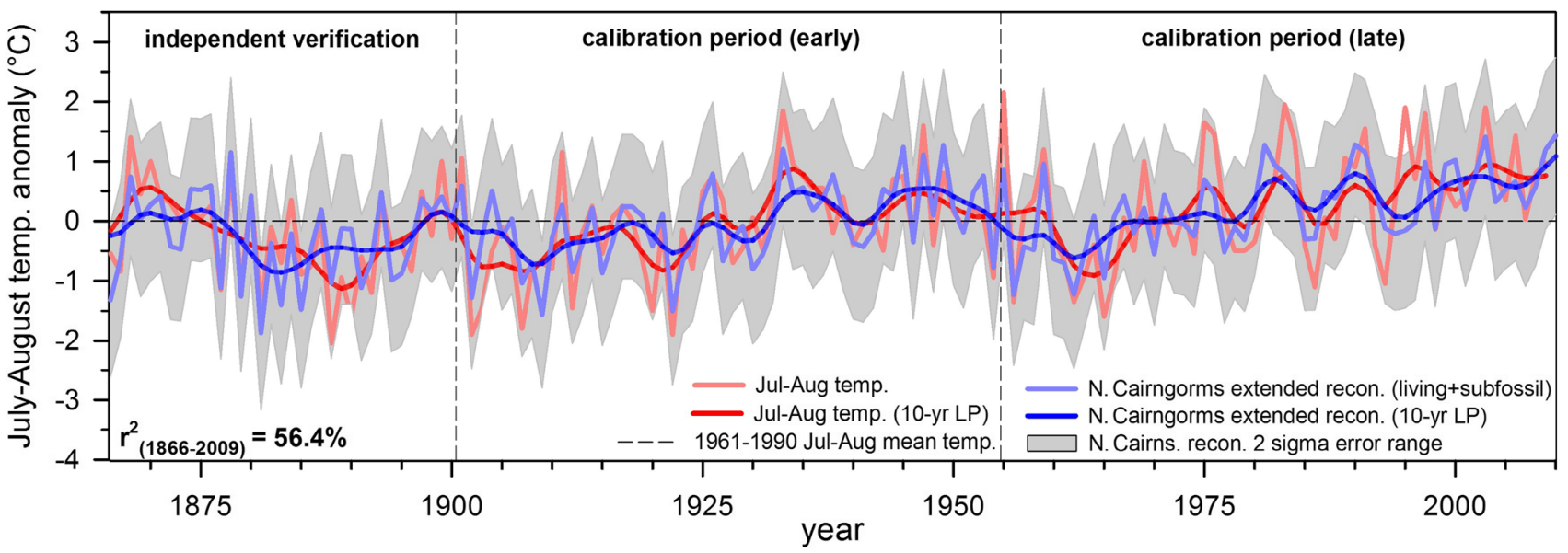

Fig. 4 Untransformed and 10-year low-pass filtered NCAIRN reconstruction (1901-2009 calibration) and observed instrumental July-August temperature including split 1901-1954 and 1955-2009 calibration and verification periods and an 1866-1900 independent verification period

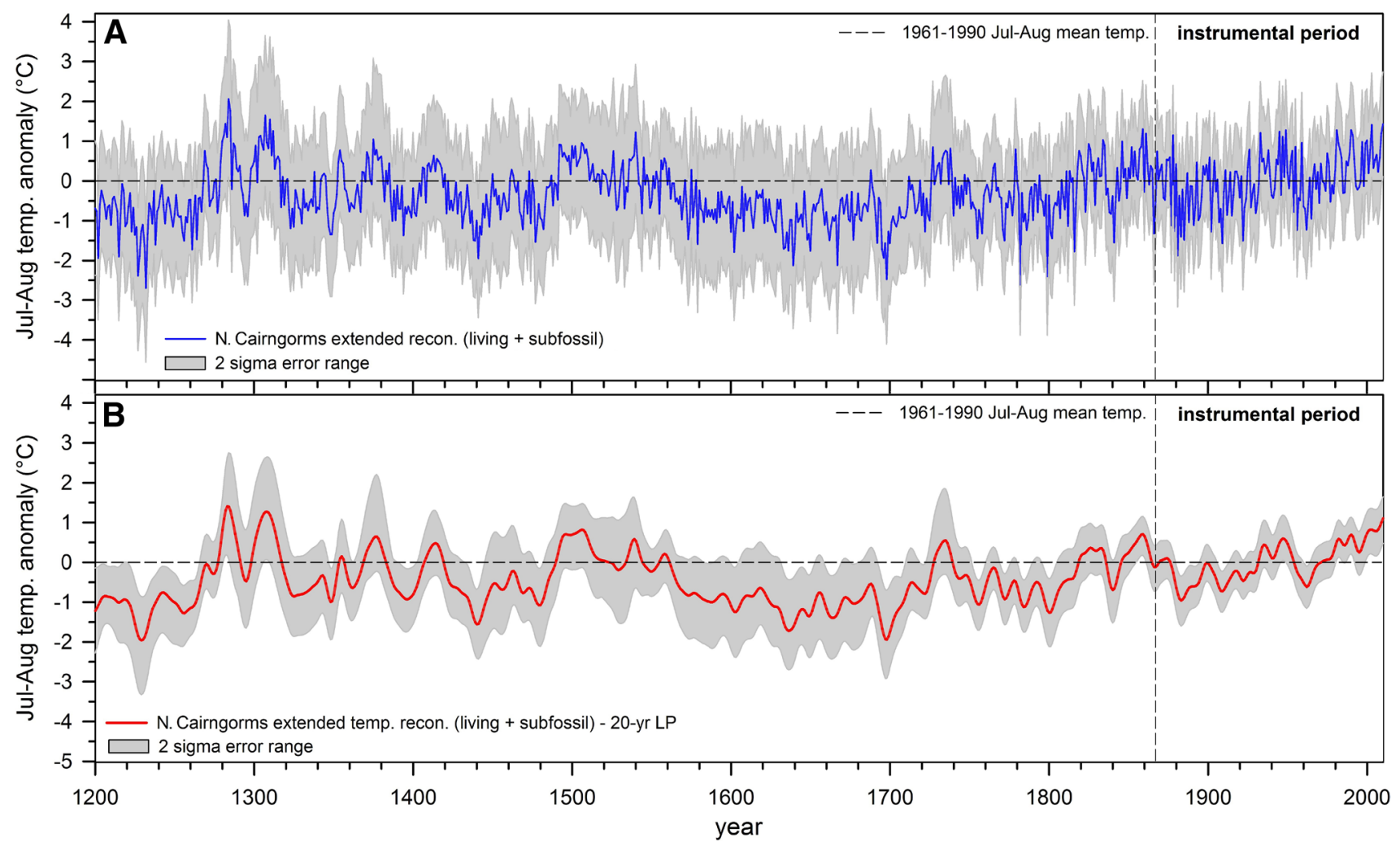

Fig. 5 NCAIRN a untransformed and b 20-year low-pass filtered reconstruction of July-August temperatures

fourteenth century warm period reflects actual climate and this period must therefore be interpreted cautiously at this time.

When examining extreme individual summers (Table 2), the top five warmest years occur in $1284,1285,1307,1310$ and 1282. However, as discussed above, if the 1300s period values are biased due to low replication and age structure, this representation of the warmest years may be misleading and caution is advised when assessing individual years as the expression of extreme years in such reconstructions may be limited (McCarroll et al. 2015). An examination of historical accounts for unusually warm years may also offer little help as documentary archives tend to focus on societally stressful extreme events which may translate into an under-representation of anomalously warm conditions. This is because (unless linked to severe drought) warm extremes 
Table 2 Ten coldest and warmest reconstructed years and five warmest and coldest reconstructed decades (anomalies relative to 1961-1990)

\begin{tabular}{|c|c|c|c|c|c|c|c|}
\hline \multicolumn{2}{|c|}{ Warm years } & \multicolumn{2}{|c|}{ Cold years } & \multicolumn{2}{|c|}{ Warm decades } & \multicolumn{2}{|c|}{ Cold decades } \\
\hline Year & Temp. anomaly & Year & Temp. anomaly & Year & Temp. anomaly & Year & Temp. anomaly \\
\hline 1284 & 2.15 & 1232 & -2.61 & $1301-1310$ & 1.07 & $1691-1700$ & -1.30 \\
\hline 1285 & 1.86 & 1782 & -2.52 & $1281-1290$ & 1.06 & $1631-1640$ & -1.27 \\
\hline 1307 & 1.74 & 1698 & -2.38 & 2001-2010 & 0.82 & $1221-1230$ & -1.11 \\
\hline 1310 & 1.64 & 1799 & -2.32 & $1501-1510$ & 0.77 & $1231-1240$ & -1.03 \\
\hline 1282 & 1.53 & 1227 & -2.30 & 1981-1990 & 0.67 & $1661-1670$ & -0.96 \\
\hline 2010 & 1.52 & 1639 & -2.04 & & & & \\
\hline 2003 & 1.50 & 1667 & -2.03 & & & & \\
\hline 1859 & 1.39 & 1441 & -1.86 & & & & \\
\hline 1990 & 1.37 & 1202 & -1.85 & & & & \\
\hline 1949 & 1.37 & 1696 & -1.84 & & & & \\
\hline
\end{tabular}

were less likely to lead to societal disruption and hardship in a country such as Scotland and were therefore less likely to be recorded than for example cold or wet extremes (Dawson 2009; Dobrovolný et al. 2010).

The most evident extended cold period is centred on the seventeenth century and extends from the late sixteenth until the early eighteenth century (although this is also one of the periods of greatest uncertainty in the reconstruction). This cold period coincides with the so-called Little Ice Age (LIA-Matthews and Briffa 2005) reported in historical and various proxy records from both the Northern and Southern Hemispheres (Büntgen and Hellmann 2014; Neukom et al. 2014) and described as a period of deteriorating climate in Scotland after 1550 (Lamb 1964). Three of the five coldest reconstructed decades (1631-1640, 1661-1670 and 1691-1700) occurred in the seventeenth century with the 1690 s representing the coldest decade in the record (Table 2$)$. The period ( 1693-1700) was marked by exceptionally cold and wet summers with widespread famine in Scotland, failed or delayed harvests and southward expansion of sea ice in the northern North Atlantic, coinciding with the effects of volcanic eruptions including the Mt Hekla eruption in 1693 and an unidentified event in 1695 (Dawson 2009; Lamb 1964; Plummer et al. 2012). Other noteworthy cold periods in the reconstruction include the 1440s, the second half of the 1700s and the pre- 1270 period, although, again, the latter should be interpreted with caution due to weak replication during that time (Fig. 2). However, historical accounts coinciding with cold periods in the NCAIRN reconstruction do suggest that severe cold winters and famines were frequent before the late thirteenth century and also occurred up to and after the middle of the fifteenth century with widespread crop failure in some years (Dawson 2009).

Exceptionally cold years appear to be well expressed. Of the most extreme single reconstructed years summarised in Table 2 the five coldest are 1232, 1782, 1698, 1799 and
1227. While early accounts are scarce and focus predominantly on cold winters, historical evidence of more recent summers, characterised by low temperature extremes, is insightful. Historical accounts, for example, suggest that the year 1799 (fourth coldest reconstructed year) was characterised by a "...remarkably cold summer..." with temperatures in Scotland well below average (Dawson 2009, p 151). Similarly, 1782 and 1698 are described as years of famine with very late and poor harvests and with very cold conditions overall (Dawson 2009; Walton 1952).

\subsection{Comparison of NCAIRN with European reconstructions}

Spatial correlations of the NCAIRN reconstruction with gridded $0.5^{\circ}$ CRU TS 3.22 (Harris et al. 2014) July-August mean temperature (Fig. 6a, b) highlight strong agreement of reconstructed and instrumental temperatures over the British Isles, particularly over Scotland and much of east and northeast England with correlations $>0.72$. Although the strength of this relationship decreases with increasing distance, it nevertheless still remains high $(r>0.64)$ over western France, Belgium and the Netherlands. Correlations $>0.4$ are observed as far away as central Spain and Portugal, parts of central Europe, western parts of the Baltic states, southwest Finland and central Sweden. Though understandably weaker, the character of this spatial pattern is similar when compared to the correlation of the ESMT instrumental temperature record with gridded temperature series around Europe (Fig. 6c).

Figure 7 compares the NCAIRN reconstruction against other temperature records for the UK including an independent "rest of the Cairngorms" (hereafter referred to as ROC) reconstruction from central Scotland (Rydval et al. 2016b), the Central England Temperature (CET) instrumental record (Parker et al. 1992) and other temperature reconstructions for the UK (Hughes et al. 1984; Lamb 
Fig. 6 Spatial plot of correlations between gridded CRU TS 3.22 (Harris et al. 2014) July-August mean temperatures and a the NCAIRN reconstruction for the United Kingdom and Ireland $\mathbf{b}$ the NCAIRN reconstruction for Europe and the $\mathbf{c}$ ESMT temperature series over the 1901-2009 period
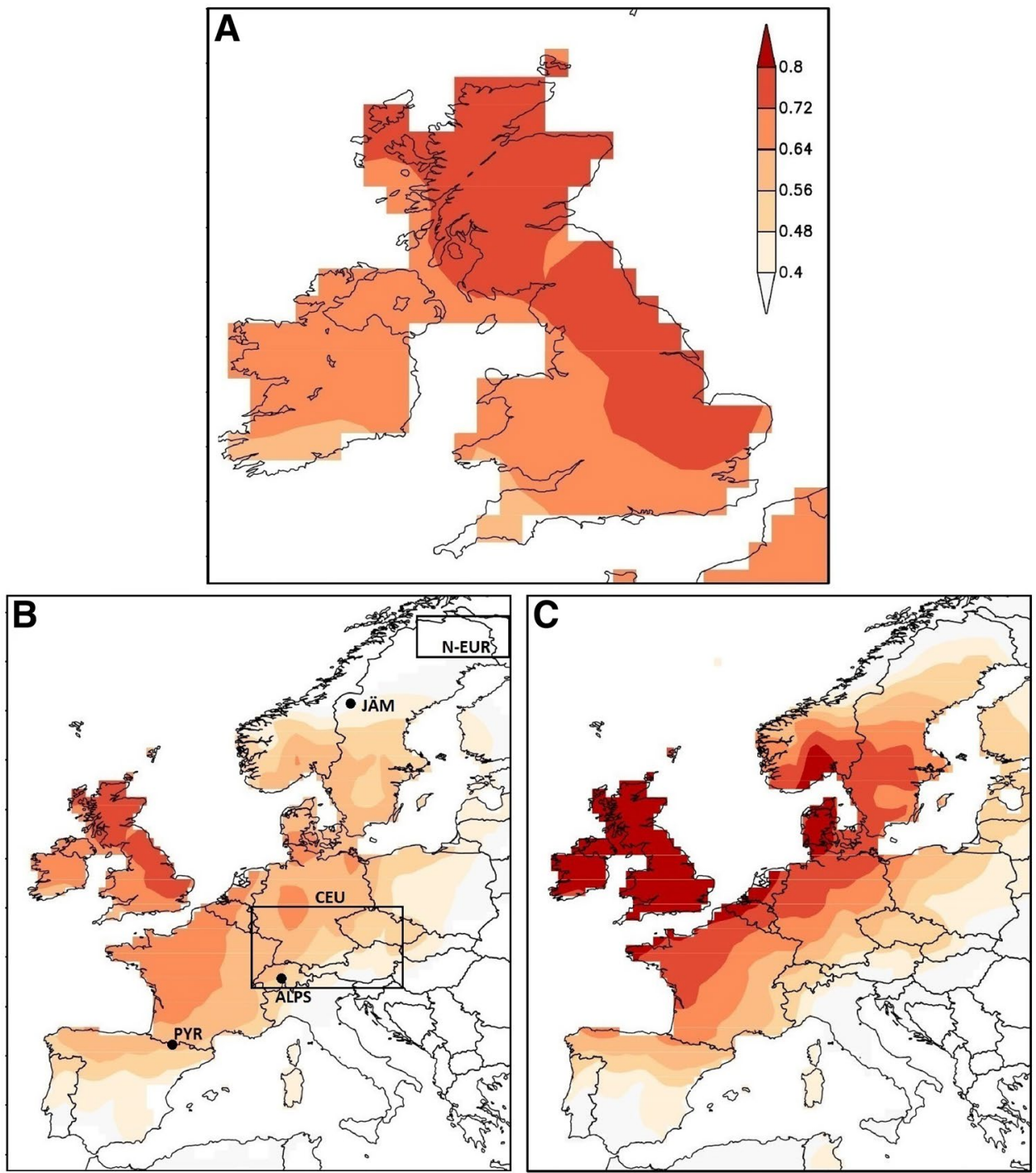

1965; Luterbacher et al. 2004) (a comparison using 20 year low-pass versions is included as Supplementary Figure S4). The ROC reconstruction, derived using a principal component regression approach using all living TR data except for the four sites used in NCAIRN (Rydval et al. 2016b), compares very well back to $\sim 1740$ (Fig. 7a). Minor trend differences and deviations in the mean level can be explained as a consequence of both applying RCS to the subfossil series in NCAIRN, whereas no RCS detrending was applied to ROC, and also to weak replication in the early sections of the living chronologies used for ROC.

Considering the distance $(\sim 500 \mathrm{~km})$ of the North Cairngorms from central England, good agreement between the records is observed back to $\sim 1800$ (Fig. 7b), with some weakening in the late twentieth century. The 1750-1800 period appears warmer in CET and a weaker correlation is also observed around that time. The records depart before $\sim 1720$ with CET showing generally warmer conditions and the correlation is also weaker in this earliest part. While uncertainties in the CET record have been extensively examined and discussed by Parker and Horton (2005) for the period after 1878, no such exercise has been undertaken for the $\sim 200$ years prior to that time. Uncertainty in the record invariably increases back in time with the incorporation of a diverse range of sources and increasing reliance on non-instrumental data such as diaries in the early parts of the record or the placement of some thermometers indoors before 1760 (Manley 1974). These circumstances present a considerable challenge to producing a single homogenised and unbiased temperature record. Such considerations have been investigated and discussed in relation to other long European instrumental temperature records as for example in Sweden (Moberg et al. 2003), the European Alps and for the Northern Hemisphere more generally (Frank et al. 2007). Manley (1974) states that the earliest part (first 

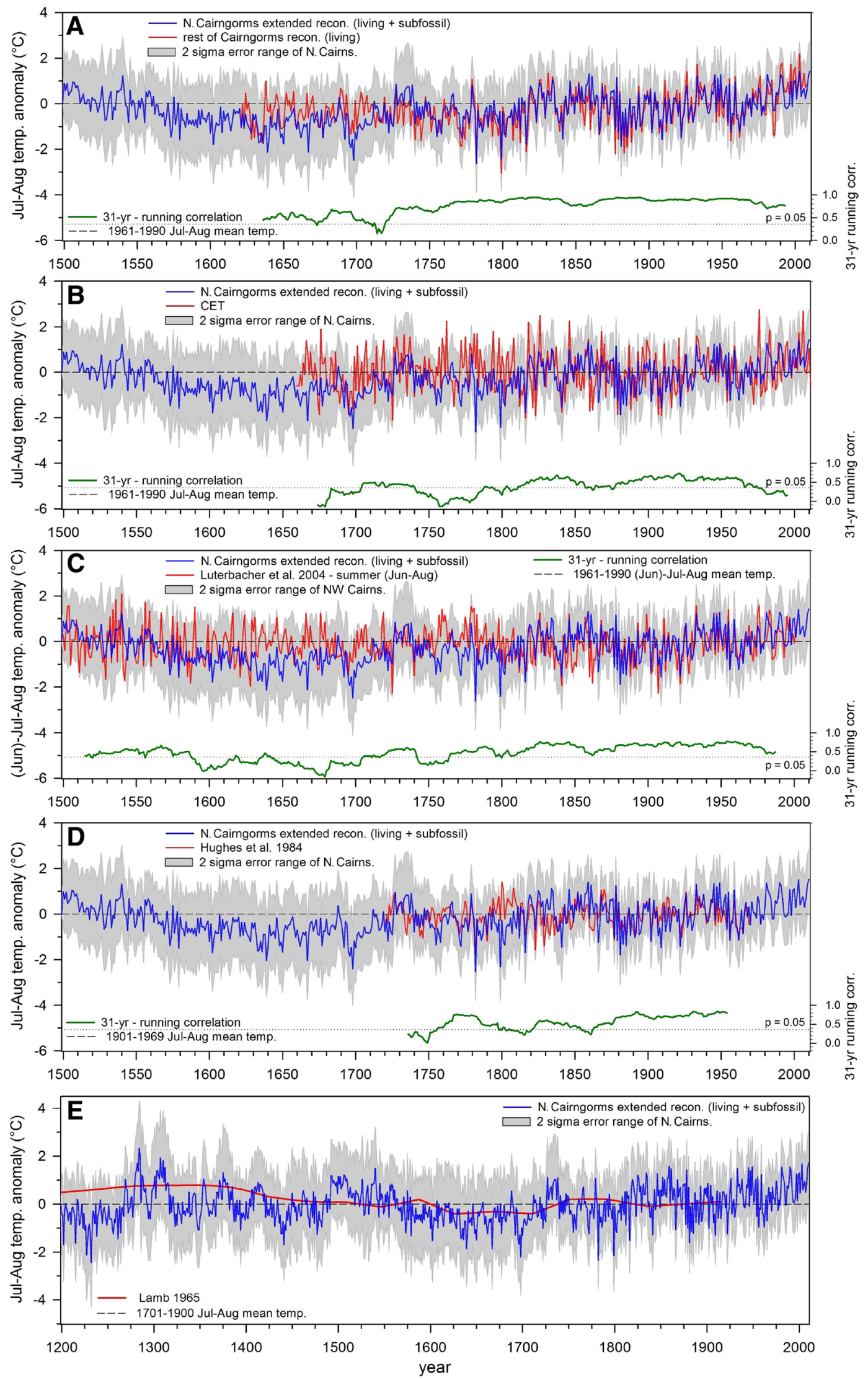
4Fig. 7 Comparison of the NCAIRN reconstruction with a a reconstruction produced using all other living chronologies from the Cairngorms, b CET July-August mean temperature, c Luterbacher et al. (2004) $0.5^{\circ}$ summer season (June-August) reconstruction for central Scotland, d Hughes et al. (1984) July-August reconstruction for Edinburgh and $\mathbf{e}$ the Lamb (1965) reconstruction of July-August temperature (digitised from Lamb 1965) — note $x$-axis scale change

$\sim 60$ years) of the record in particular should be considered less reliable.

The generally flatter Luterbacher et al. (2004) June-August reconstruction (Fig. 7c) shows a centennial departure around the mid-1600s and may possibly also be an expression of limited low frequency information contained in that record which also includes historical documentary evidence. Limitations in the use of historical indices to capture low frequency trends is a known issue (Dobrovolný et al. 2010). Additionally, it is uncertain whether truncation of TR records was performed in Luterbacher et al. (2004) for weakly replicated early sections of the records as this would also affect reconstruction quality in the earlier periods. In general, the correlation between the two series decreases back in time with particularly weak agreement around 1600 and the late seventeenth century, although this improves again in the sixteenth century. The variable degree of agreement can partly be explained by the changing representation of various predictor records from different locations through time in the Luterbacher reconstruction. The excellent agreement with NCAIRN after $\sim 1800$ is undoubtedly due to the inclusion of Scottish instrumental temperature records (including Edinburgh from 1764 onwards and Aberdeen from 1870). As CET is also included as a predictor in the Luterbacher reconstruction, it undoubtedly strongly influences the late seventeenth to late eighteenth century estimates. Luterbacher et al. (2004) acknowledged that inhomogeneities in early (mid-eighteeth to mid-nineteenth century) instrumental records are a potential source of uncertainty, possibly causing a bias towards warmer estimates. The sixteenth century agreement is surprising as (1) this part of the Luterbacher record appears to be based on TR data from northern Norway and documentary evidence from the Low Countries and (2) because the sixteenth century is a period of weaker signal strength in NCAIRN based on EPS results (Fig. 2b). Therefore, this period of coherence with Luterbacher et al. (2004) provides some re-assurance about the reliability of this particular period in NCAIRN.

Given that NCAIRN and the Hughes et al. (1984) reconstructions are entirely independent, agreement with Hughes is good over most periods (Fig. 7d), though weaker in the earliest common period. The most apparent departure after 1800 occurs during a known period of increased disturbance related to more intensive tree harvesting associated with the Napoleonic Wars (Oosthoek 2013; Rydval et al. 2016a; Smout et al. 2005), which may be partly reflected in the Hughes record. The utilisation of polynomials to detrend TR series in the Hughes reconstruction presumably severely restricted the retention of any lower frequency trends. However, there is no indication of divergence when compared to NCAIRN as there appears to be little longterm trend in the period of overlap, although poor verification results in the Hughes record before 1810 are reported and the study cautions that the earliest section of the reconstruction may be less reliable (Hughes et al. 1984). Interestingly, although more qualitative in nature, the Lamb (1965) historical observation-based reconstruction suggests that the seventeenth century was a colder period (Fig. 7e) and also indicates the existence of a warmer period centred on 1300 . While this qualitative agreement with NCAIRN is only indicative and does not in any way substantiate the existence of a warmer period around that time, it also highlights that such a possibility cannot be ruled out without careful consideration and evaluation.

Correlations between the UK instrumental and proxy temperature records discussed above (excluding the Lamb reconstruction) are presented in Table 3 . The high correlation between CET and the Luterbacher et al. (2004) reconstruction, and the relatively weaker agreement with the three Scottish reconstructions indicates a high degree of dependence of the Luterbacher record on CET. The fact that the ROC reconstruction correlates more strongly with other records than NCAIRN is not surprising as the former includes data from 11 site chronologies-also including MXD data. Overall, the Hughes record shows the lowest correlation of the Scottish reconstructions with other records-indicating that the new data express a substantial update on this original work. An additional comparison of NCAIRN and ROC with an instrumental temperature record from Gordon Castle in northeast Scotland for 1781-1827 and 1879-1974 (Fig. 1; Table 3) shows very strong relationships between the instrumental series and the reconstructions over both periods $\left(\mathrm{r}_{(1879-1974)}=0.72\right.$ and $r_{(1781-1827)}=0.70$ for NCAIRN; $r_{(1879-1974)}=0.69$ and $\mathrm{r}_{(1781-1827)}=0.64$ for ROC). These consistently high correlations with Gordon Castle provide additional validation of the temporal stability of NCAIRN and ROC outside the calibration period.

We compare NCAIRN with European temperature reconstructions (Fig. 8), including central Europe (CEUDobrovolný et al. 2010), the Pyrenees (PYR—Liñán et al. 2012), the European Alps (ALPS-Büntgen et al. 2006), Jämtland in central Sweden (JÄM-Zhang et al. 2015) and northern Fennoscandia (N-EUR-Esper et al. 2014; Matskovsky and Helama 2014). It is possible to distinguish multidecadal scale periods of reconstruction agreement and disagreement within the spatial context of the location of those records (Fig. 6; see also Supplementary Figure S5 
Table 3 Correlation matrix of NCAIRN reconstruction and other UK temperature records

\begin{tabular}{|c|c|c|c|c|}
\hline & NCAIRN & ROC & CET & Luterbacher \\
\hline \multicolumn{5}{|l|}{ 1721-1969 } \\
\hline ROC & $\begin{array}{l}r=0.867 \\
p<0.001\end{array}$ & - & - & - \\
\hline CET & $\begin{array}{l}\mathrm{r}=0.400 \\
\mathrm{p}<0.001\end{array}$ & $\begin{array}{l}\mathrm{r}=0.418 \\
\mathrm{p}<0.001\end{array}$ & - & - \\
\hline Luterbacher & $\begin{array}{l}r=0.479 \\
p<0.001\end{array}$ & $\begin{array}{l}\mathrm{r}=0.509 \\
\mathrm{p}<0.001\end{array}$ & $\begin{array}{l}\mathrm{r}=0.740 \\
\mathrm{p}<0.001\end{array}$ & - \\
\hline Hughes & $\begin{array}{l}\mathrm{r}=0.489 \\
\mathrm{p}<0.001\end{array}$ & $\begin{array}{l}r=0.546 \\
p<0.001\end{array}$ & $\begin{array}{l}\mathrm{r}=0.363 \\
\mathrm{p}<0.001\end{array}$ & $\begin{array}{l}\mathrm{r}=0.467 \\
\mathrm{p}<0.001\end{array}$ \\
\hline \multicolumn{5}{|l|}{ 1659-2002 } \\
\hline ROC & $\begin{array}{l}r=0.786 \\
p<0.001\end{array}$ & - & - & - \\
\hline CET & $\begin{array}{l}r=0.367 \\
p<0.001\end{array}$ & $\begin{array}{l}\mathrm{r}=0.400 \\
\mathrm{p}<0.001\end{array}$ & - & - \\
\hline Luterbacher & $\begin{array}{l}r=0.441 \\
\mathrm{p}<0.001\end{array}$ & $\begin{array}{l}\mathrm{r}=0.519 \\
\mathrm{p}<0.001\end{array}$ & $\begin{array}{l}r=0.760 \\
p<0.001\end{array}$ & - \\
\hline \multicolumn{5}{|l|}{ Gordon castle } \\
\hline $1781-1827$ & $\begin{array}{l}r=0.704 \\
p<0.001\end{array}$ & $\begin{array}{l}\mathrm{r}=0.641 \\
\mathrm{p}<0.001\end{array}$ & - & - \\
\hline 1879-1974 & $\begin{array}{l}r=0.722 \\
p<0.001\end{array}$ & $\begin{array}{l}r=0.690 \\
p<0.001\end{array}$ & - & - \\
\hline
\end{tabular}

for a comparison of instrumental temperature targets for NCAIRN and other European records). Large differences exist in the magnitude and timing of warmer and colder episodes between most of the examined reconstructions, which can be expected considering the decreasing spatial correlation of Scottish TR and instrumental data over Europe with increasing distance (Fig. 6b, c). However, it is also important to examine agreement and disagreement between records in the context of the reconstructed target season (which is broader than July-August in the case of the Jämtland, Pyrenees, Alps and N-EUR), standardisation method applied and reconstruction uncertainty as such factors can also affect coherence between the series.

Based on the correlation between NCAIRN target season instrumental data with instrumental target series of the other reconstructions, best agreement would be expected with CEU $(r=0.55)$ followed by PYR $(r=0.52)$, ALPS $(r=0.47)$, JÄM $(r=0.44)$ and N-EUR $(r=0.28)$. Correlations between the European reconstructions (Table 4) are largely consistent with geographical distance between the locations as reflected for example by very good agreement between N-EUR and JÄM $\left(\mathrm{r}_{(1500-2002)}=0.63\right)$ or the high frequency coherence between CEU and ALPS $\left(r_{(1500-2002)}=0.56\right)$. Interestingly, although some of the European records are not significantly correlated (or only correlate very weakly) with each other, the new Scotland reconstruction correlates significantly with all examined records and most strongly with the Alps $\left(\mathrm{r}_{(1500-2002)}=0.46\right)$ and central Scandinavia $\left(\mathrm{r}_{(1500-2002)}=0.38\right)$ followed by central Europe $\left(\mathrm{r}_{(1500-2002)}=0.31\right)$, N-EUR $\left(r_{(1500-2002)}=0.21\right)$ and the Pyrenees $\left(r_{(1500-2002)}=0.21\right)$.

The reason for the weaker than expected correlation with PYR is unclear, though it may be related to the broader seasonal window (May-September) of that reconstruction and its weaker lower frequency match with instrumental data (Liñán et al. 2012). Poor late eighteenth century summer season verification statistics and a weak common signal between the historical records used for August around the 1650-1700 period in the CEU reconstruction may also account for the weaker correlation with NCAIRN at this time. While some degree of agreement with the other European records is expected considering Scotland's location (Fig. 6), the correlations suggest that the Scottish record can be seen as intermediary as it shares temporally changing common variance with records from northern to southern Europe. NCAIRN arguably must also express unique variability related to North Atlantic climate dynamics.

The greater variance of N-EUR and CEU in Fig. 8 relative to the other reconstructions can be explained by the application of scaling in the case of N-EUR (instead of regression used for calibration of the other records with the exception of ALPS which also used scaling and PYR which used various approaches) and because CEU was based on historical documentary evidence. With the exception of CEU (and PYR which employed several methods), standardisation of all other records was performed using various forms of RCS standardisation and so would be expected to express low frequency trends well. Although Büntgen et al. (2006) argue that an offset between warmer instrumental and cooler reconstructed temperatures before $\sim 1820$ is likely a consequence of unreliable early instrumental temperature data, it is also possible that the reconstruction may over-estimate the extent of cooling prior to that time.

All six records show a warmer interval in the period leading up to the 1950s (see Supplementary Figure S5), although it is less distinct in the CEU reconstruction. While largely absent from other records, the $\sim 1500$ s warming in the Scotland reconstruction is also present in the central Sweden and CEU records. Although the two Scandinavian records indicate warmer conditions before $\sim 1200$, only the Jämtland reconstruction suggests a warmer period around the mid-thirteenth century that is comparable to the twentieth/twenty-first century warming in that record, though it is present ca. 50 years earlier than in NCAIRN-a period which also coincides with greater uncertainty (lower EPS) in the Jämtland record and so should also be interpreted with caution. The absence of a distinct warm episode around 1300 in any of the other records other than NCAIRN supports the notion that the warm estimates for 


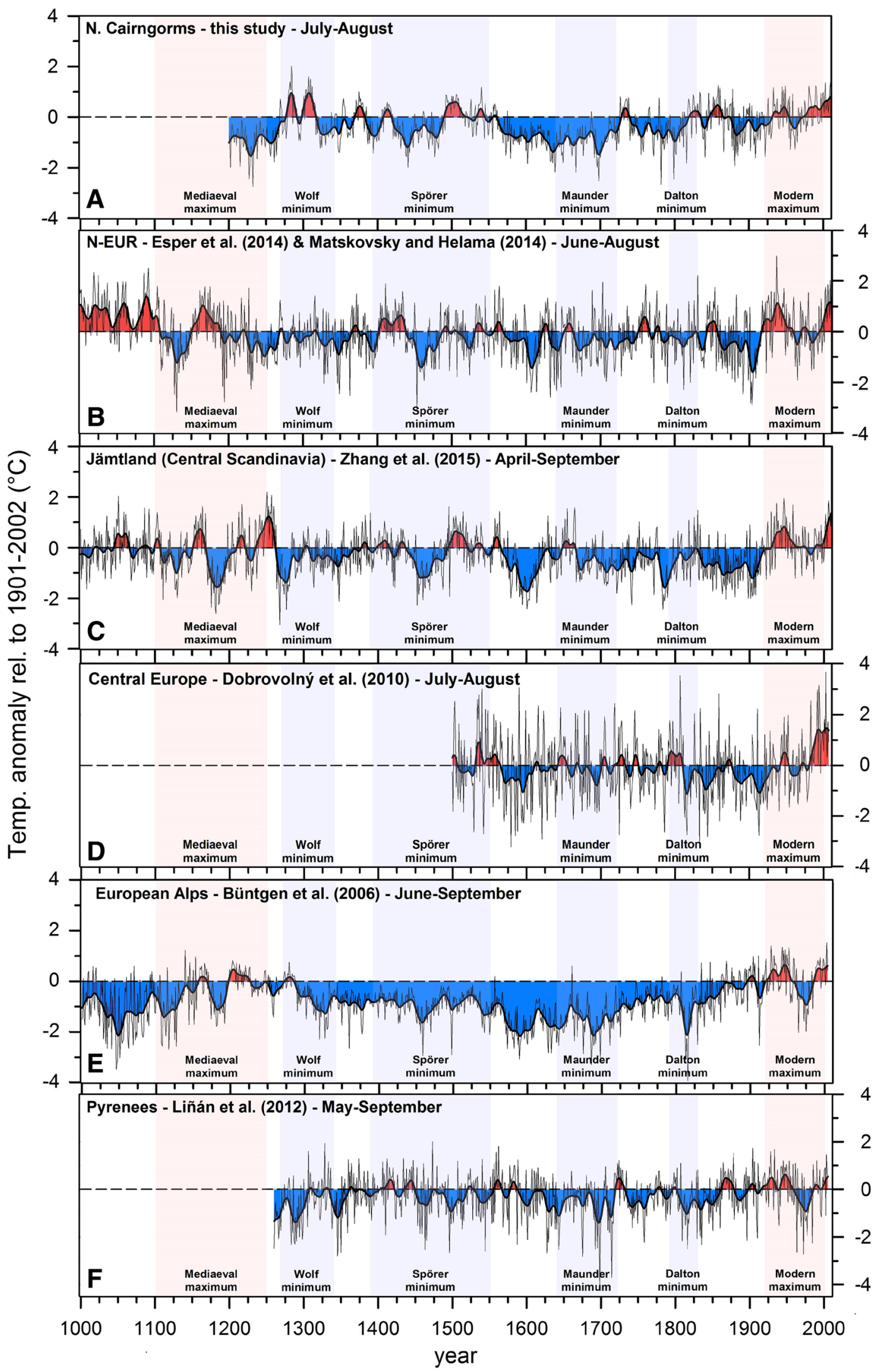

Fig. 8 Comparison of temperature reconstructions including a NCAIRN, b Northern Europe, c Central Scandinavia, d Central Europe, $\mathbf{e}$ the European Alps and the $\mathbf{f}$ Pyrenees. (Periods of solar minima and maxima are highlighted; Jirikowic and Damon 1994; Usoskin et al. 2007; Wagner and Zorita 2005) 
Table 4 Correlation matrix of the NCAIRN reconstruction and European temperature records using untransformed, 10-year Gaussian-filtered high-pass (HP) and low-pass (LP) series (results significant at the $95 \%$ confidence level are highlighted in bold font)

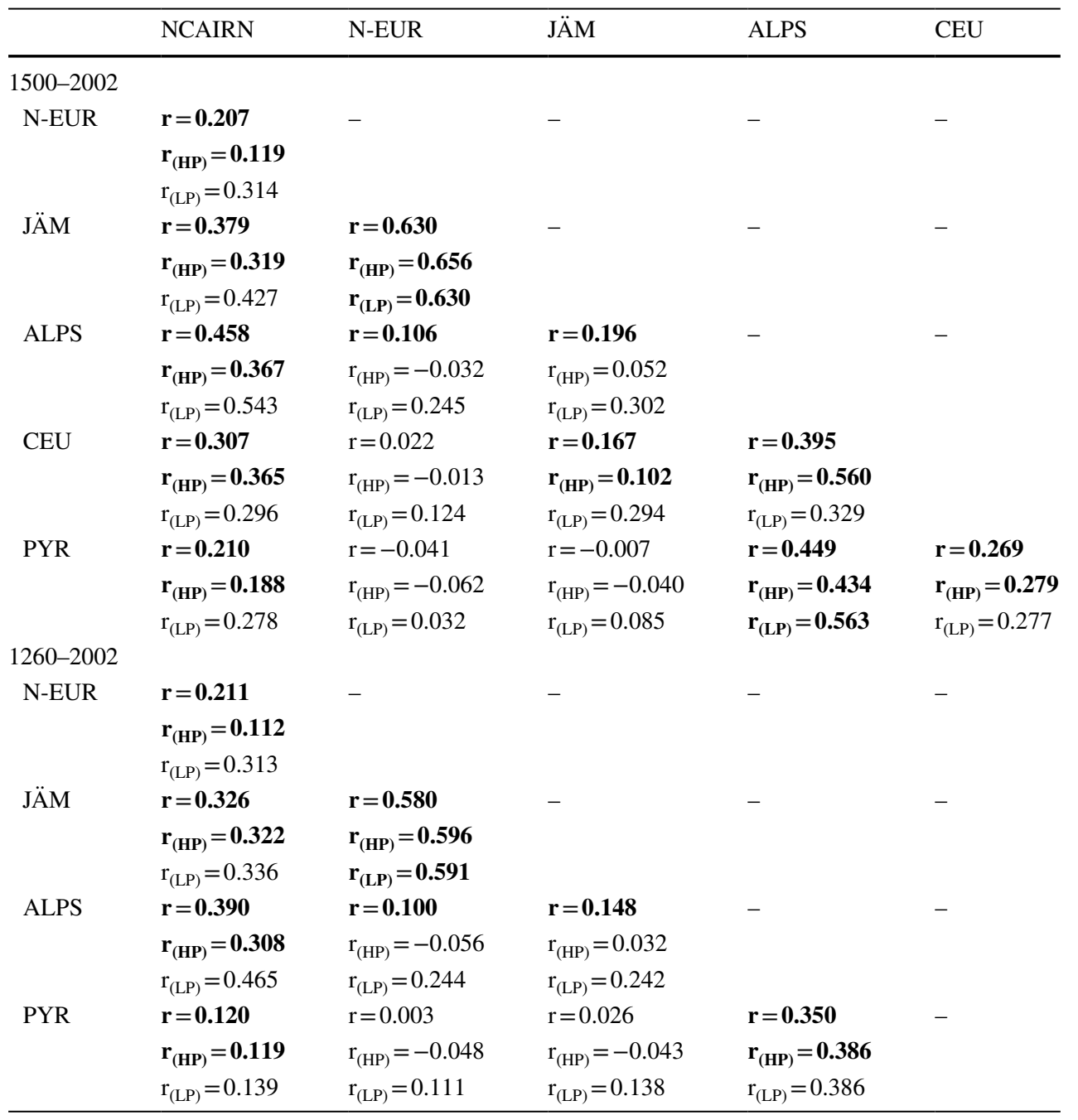

this period may be an artefact of juvenile detrending bias in a period of low replication. Nonetheless, its existence cannot be entirely ruled out based on this evidence alone as there is also some disagreement between the two reconstructions from northern Europe regarding the timing and magnitude of warm and cold events especially in the early periods.

There is reasonable agreement in general between the records regarding protracted cold periods which occur during the LIA and specifically around the Maunder solar minimum centred on the second half of the seventeenth century and to some extent also around the latter part of the fifteenth century coinciding with part of the Spörer minimum (Usoskin et al. 2007). The second half of the 1400s appears as a notably cold period in all of the records with the exception of the Pyrenees where it is less pronounced. However, although the exceptional cold period around 1700 in NCAIRN also stands out in the European Alps and Pyrenees records, the period is less apparent in the CEU, Jämtland and N-EUR reconstructions. There are also greater regional differences in the Dalton minimum period (Wagner and Zorita 2005). Specifically, the period of greatest cooling around that time is before 1800 in the NCAIRN and Jämtland reconstructions but after 1800 in the Central Europe, European Alps and Pyrenees records while only minimal cooling is noted at this time in the N-EUR record.

\subsection{Exploring forcing of extreme years}

As discussed above, and detailed in Table 2, there are a number of significant extreme warm and cold years expressed in the NCAIRN reconstruction. Understanding the forcing mechanisms of such annual extremes is fundamental towards understanding the climate dynamics controlling Scottish summer temperatures. The results of the SEA are presented in Fig. 9 (see Table 5 for a list of events). The GAO results (Fig. 9a) indicate a significant but moderate mean cooling response of $0.25^{\circ} \mathrm{C}$ relative to pre-eruption conditions in the first post-eruption year in the NCAIRN record. Using the Sigl et al. (2015) data, the mean 

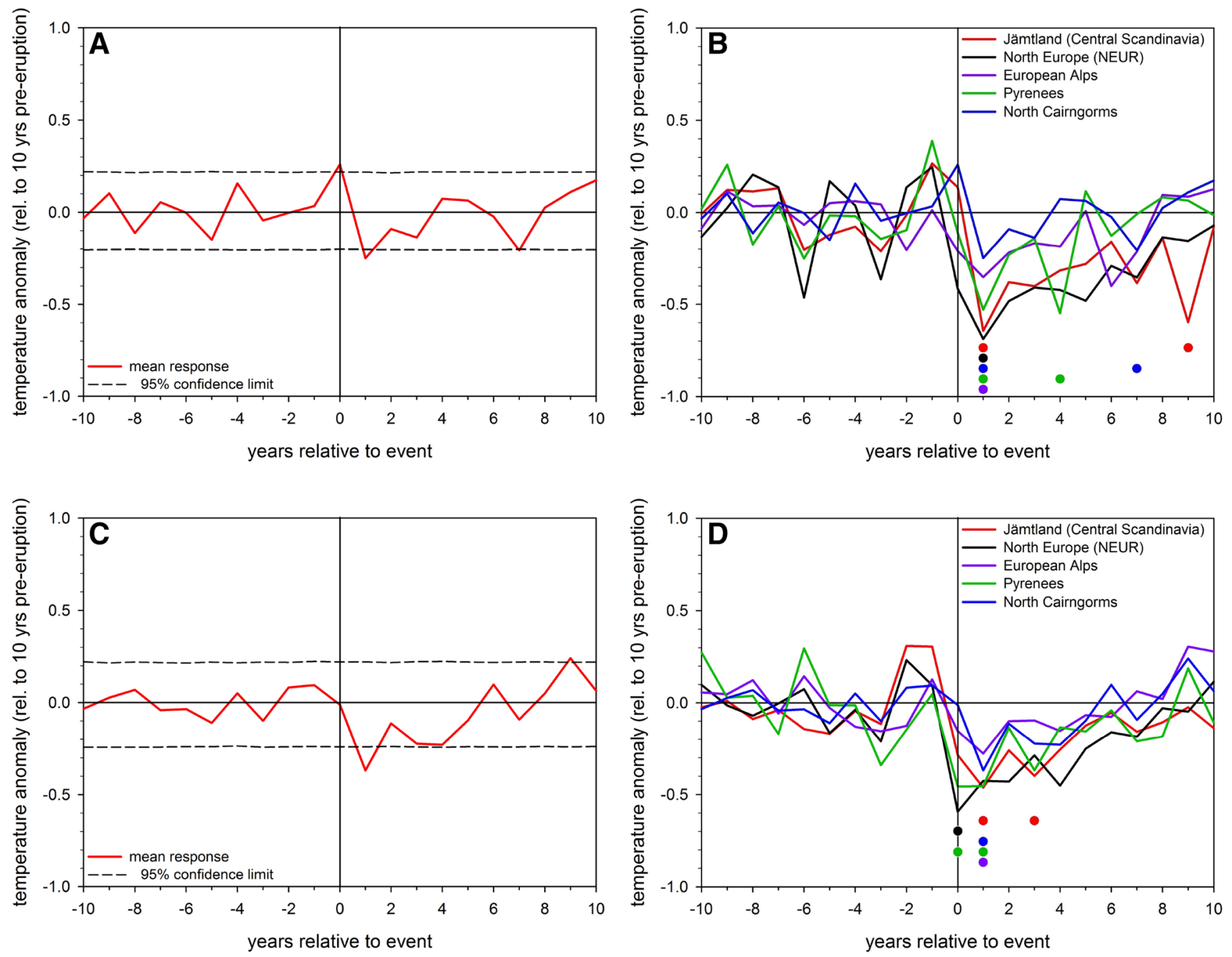

Fig. 9 Superposed Epoch Analysis of the response to volcanic eruptions in $\mathbf{a}, \mathbf{c}$ the NCAIRN reconstruction and $\mathbf{b}, \mathbf{d}$ other European temperature reconstructions for the 1300-2000 period. a, b represent all events based on the Gao et al. (2008) and c, d on the Sigl et al.

post volcanic cooling is slightly greater at $0.37^{\circ} \mathrm{C}$. While the SEA results are noisy, the response to some individual events may be clearer. For example, the single largest temperature reduction in NCAIRN (on the order of $\sim 2{ }^{\circ} \mathrm{C}$ ) compared to pre-eruption conditions occurred in 1816 following the eruption of Tambora in 1815, although this year is only the 15th coldest reconstructed year in NCAIRN.

As well as NCAIRN, all of the examined European records consistently show significant cooling 1 year following volcanic events regardless of whether the GAO or SIGL lists are used with the exception of NEUR which shows a response in the year of the event using the SIGL list. There are, however, some additional differences when using the GAO and SIGL data-sets. For example, the Pyrenees reconstruction additionally shows a significant cooling response in year zero using the SIGL events whereas
(2015) records. See Table 5 for details. Coloured dots in b, d indicate significantly ( $95 \%$ bootstrap-10,000 iterations) cooler post-eruption years in each record. Year 'zero' on the $x$-axis represents the year of the recorded event

using the GAO list the fourth post-event year is significant instead. In comparison to the other records, the NCAIRN response to volcanic events using the GAO list is muted, which may perhaps be an expression of the oceanic influence on climate in Scotland. However, from this analysis it is also quite clear that the SEA results are sensitive to the specific list of events selected (see also discussion in Esper et al. 2013).

The results may additionally be affected by factors such as the temporal uncertainty of the sulphate deposition records and (when examining individual regional temperature reconstructions) differences in the spatial distribution (and therefore also the light scattering influence) of stratospheric sulphate aerosols which will also differ from event to event (Gao et al. 2008). It can therefore be expected that the expression of post-volcanic cooling from individual 
Table 5 Overview of volcanic event years for SEA in Fig. 9 including $\mathrm{NH}$ sulphate aerosol injection events $>15 \mathrm{Tg}$ from Gao et al. (2008)

\begin{tabular}{|c|c|c|c|c|c|}
\hline Event name & location & GAO & S. injection $(\mathrm{Tg})$ & SIGL & $\begin{array}{l}\text { S. } \\
\text { deposition } \\
\left(\mathrm{kg} \mathrm{km}^{-2}\right)\end{array}$ \\
\hline Unknown & Unknown & 1328 & 19.7 & 1329 & 25.6 \\
\hline Unknown & Unknown & & & 1345 & 27.9 \\
\hline Unknown & Unknown & 1452 & 44.6 & 1453 & 24.8 \\
\hline Kuwae & Vanuatu & 1459 & 21.9 & 1458 & 39.0 \\
\hline Bardarbunga (Veidivotn) & Iceland & & & 1477 & 27.0 \\
\hline Hekla & Iceland & & & 1512 & 16.7 \\
\hline Colima & Mexico & 1584 & 24.2 & 1585 & 19.5 \\
\hline Huaynaputina & Peru & 1600 & 46.1 & 1601 & 39.2 \\
\hline Parker Peak & Philippines & 1641 & 33.8 & 1641 & 44.2 \\
\hline Shiveluch & Kamchatka & & & 1646 & 16.8 \\
\hline Tarumai & Japan & & & 1667 & 20.5 \\
\hline Unknown & Unknown & & & 1695 & 28.6 \\
\hline Unknown & Unknown & 1719 & 31.5 & & \\
\hline Lanzarote & Canary Islands & & & 1729 & 27.8 \\
\hline Tarumai & Japan & & & 1739 & 20.7 \\
\hline Laki & Iceland & 1783 & 93.0 & 1783 & 135.8 \\
\hline Unknown & Unknown & 1809 & 27.6 & 1809 & 34.6 \\
\hline Tambora & Indonesia & 1815 & 58.7 & 1815 & 39.7 \\
\hline Babuyan & Philippines & 1831 & 17.0 & 1832 & 28.0 \\
\hline Cosiguina & Nicaragua & 1835 & 26.4 & 1836 & 23.3 \\
\hline Makian & Indonesia & & & 1862 & 16.2 \\
\hline Krakatoa & Indonesia & & & 1884 & 17.0 \\
\hline Katmai & Alaska & & & 1912 & 28.6 \\
\hline Unknown & Unknown & & & 1926 & 15.7 \\
\hline Pinatubo & Indonesia & 1991 & 15.1 & 1991 & 37.2 \\
\hline
\end{tabular}

SIGL represents volcanic events in Sigl et al. (2015) with Greenland sulphate deposition $>15 \mathrm{~kg} \mathrm{~km}^{-2}$ regional records may be less clear compared to one based on a larger scale (e.g. hemispheric) analysis (Schneider et al. 2015; Stoffel et al. 2015; Wilson et al. 2016). Furthermore, although limited to a small number of instances and unlikely to produce a significant bias, some additional limitation of the SEA analysis may result from overlapping windows of certain events (e.g. 1809 and 1815) which means that the response to some eruptions may not be entirely independent of others.

Ultimately, although major volcanic events are expressed in the NCAIRN record, there are clearly significant cold reconstructed summers which are not coincident with these externally forced volcanic perturbations of the atmosphere (Table 2). Some other factor must be influencing these reconstructed cold summers which we hypothesise must be related to internal dynamics of the climate system of the North Atlantic sector. To test this, we perform a spatial composite analysis for extreme $(> \pm 1$ standard deviation away from a running 21-year local median high pass filter) warm and cold years against the $500 \mathrm{hPa}$ geopotential height field using both observed (Compo et al. 2011) and reconstructed (Luterbacher et al. 2002) datasets. Clear consistent patterns emerge for both observed (Fig. 10a, 1851-1999; C20Cv2 (Compo et al. 2011), $\mathrm{n}_{\text {warm }}=6$, $\mathrm{n}_{\text {cold }}=11$ ) and reconstructed (Fig. 10b, 1659-1999; Luterbacher et al. 2002, $\mathrm{n}_{\text {warm }}=8, \mathrm{n}_{\text {cold }}=21$ ) extreme values, although the spatial expression of the height anomalies is larger using the reconstruction. Highly similar patterns are also obtained for SLP (not shown). These obtained patterns are very similar to those of the negative and positive phases of the summer North Atlantic Oscillation (SNAO, Folland et al. 2009). The correlation between NCAIRN and the SNAO (1851-2010) is $0.30(\mathrm{p}<0.01)$. The composite results suggest that extreme high (low) temperature years are associated with the positive (negative) phase of the SNAO, where the storm track is shifted northwards (southwards) yielding anticyclone (cyclonic) conditions over Scotland causing warm and dry (mild and wet) summers. The frequency and distribution of warm and cold temperature extremes in the new Scottish reconstruction indicates that the negative phase of the SNAO dominated during the LIA, and that the high frequency of positive SNAO years 


\section{A Z500 - Observations (1851-1999)}
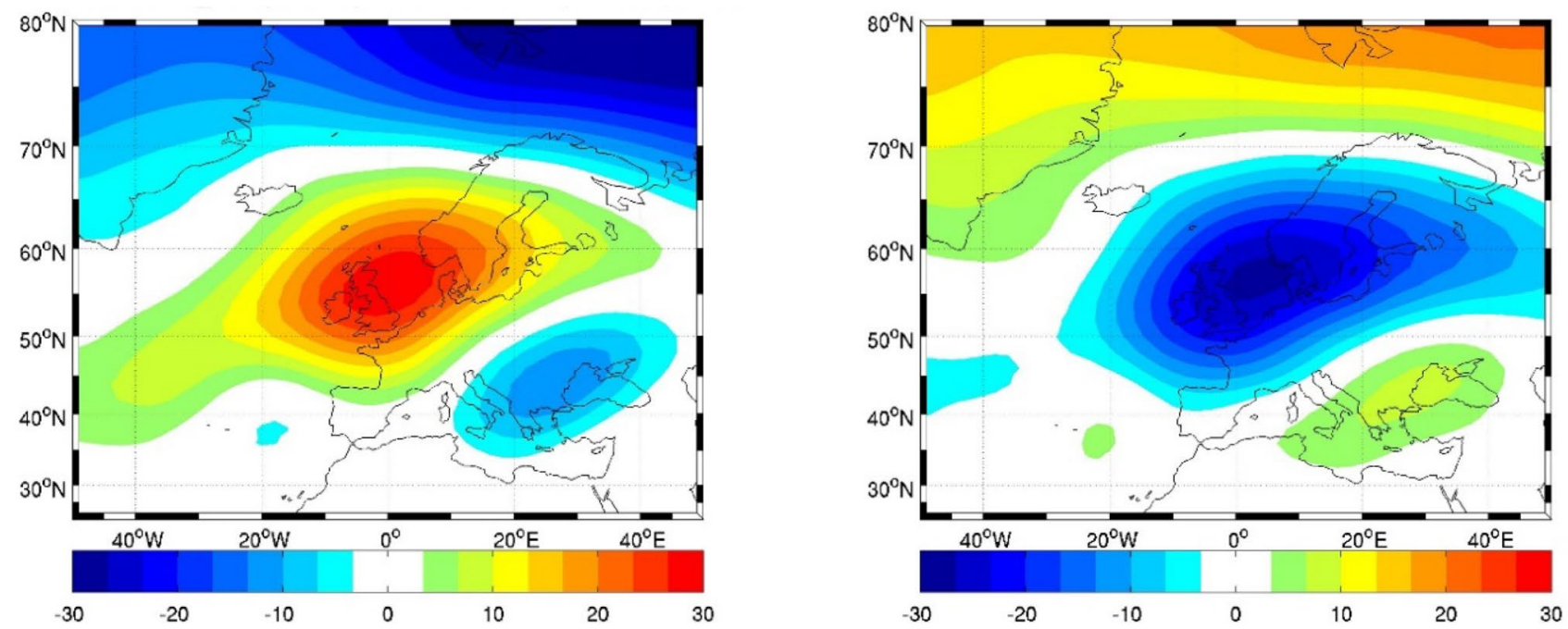

\section{B Z500 - Reconstruction (1659-1999)}

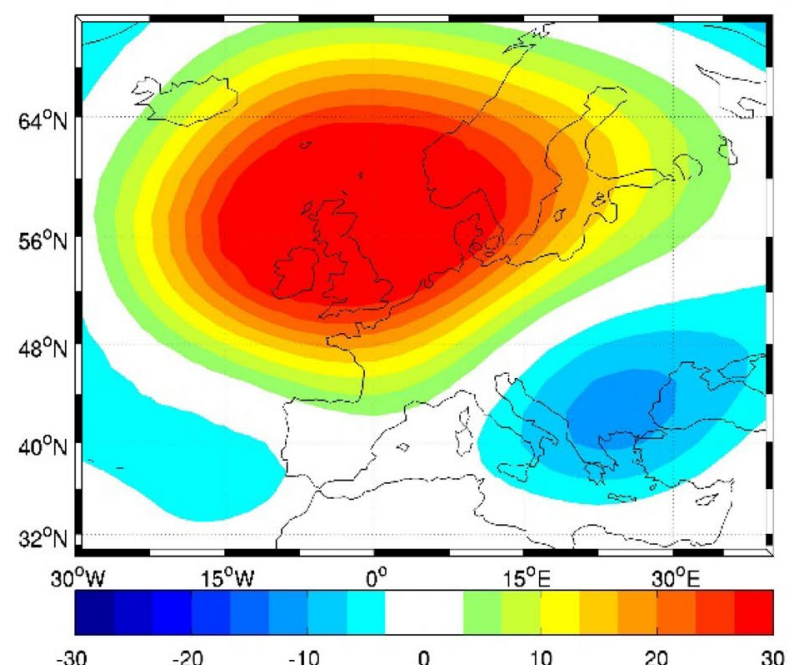

Fig. 10 a Observed twentieth century reanalysis data (C20C v2c, Compo et al. 2011) $500 \mathrm{hPa}$ geopotential height (Z500) composite anomalies (in meters) for June-August during years with (left) extreme warm $(1859,1878,1933,1949,1955,1959)$ and (right) cold (1866, 1867, 1879, 1881, 1883, 1885, 1902, 1909, 1922, 1956, 1962) reconstructed summer temperatures in Scotland (1851-1999).

during the twentieth century was anomalous, at least since the mid-seventeenth century, possibly related to a northward shift in the jet stream.

\subsection{Further discussion}

Other researchers have highlighted potential limitations of using subfossil material from lakes to make inferences about past climatic conditions. For example, Linderholm

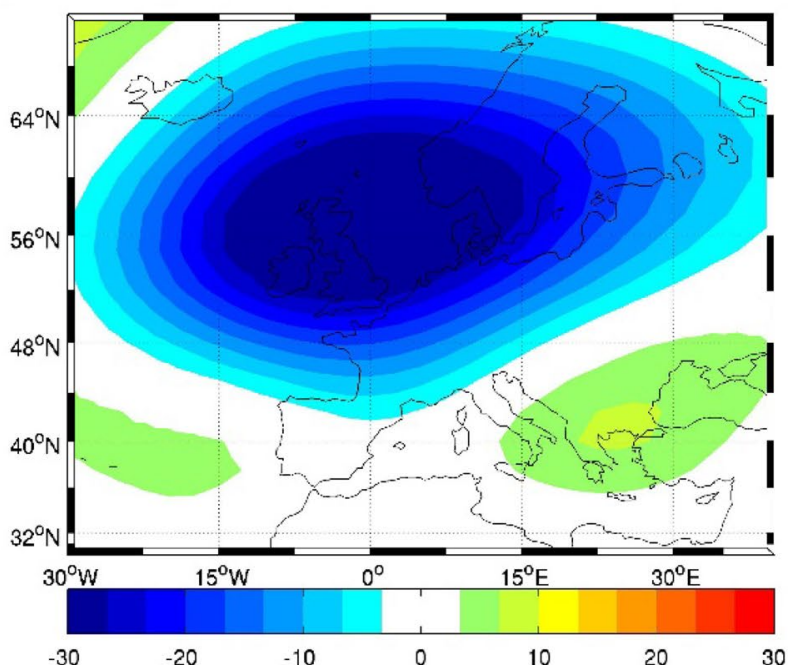

b Reconstructed $500 \mathrm{hPa}$ geopotential height composite anomalies (Luterbacher et al. 2002) for June-August during years with (left) extreme warm $(1688,1779,1859,1878,1933,1949,1955,1959)$ and (right) cold (1667, 1698, 1722, 1755, 1772, 1782, 1799, 1816, 1823, 1841, 1866, 1867, 1879, 1881, 1883, 1885, 1902, 1909, 1922, 1956, 1962) reconstructed summer temperatures in Scotland (1659-1999)

et al. (2014) cautioned that the sensitivity of lakeshore pine trees to temperature can be reduced in periods with wetter conditions as they may respond differently when compared to trees growing at tree-line. Although in Scandinavia some bias potential of lakeshore and non-lakeshore material has been noted (Esper et al. 2012), this is less relevant in the Scottish case since the original provenance of the subfossil samples is likely more spatially heterogeneous. Many of the lake-preserved subfossil samples had clear evidence 
of felling such as axe and saw marks and were also likely felled from a wider region (i.e. including non-lakeshore areas) and transported to the lakes overland or via rivers as a result of logging activities. The living trees were therefore sampled both close to and away from lakeshore environments.

It is worth mentioning that the availability of subfossil material in Scotland is limited in the sense that sampling sites cannot be strategically selected for proximity to upper tree-line as would be the ideal for finding temperature limited trees. Rather, the availability of subfossil material is restricted to specific lakes with suitable conditions for preservation. Therefore, the sites included in the NCAIRN reconstruction are located at an elevational range of 260-420 m a.s.l. and are therefore at least $200 \mathrm{~m}$ below the current theoretical tree-line (Miller and Cummins 1982). Nevertheless, strong calibration and verification results and the generally good agreement with the ROC reconstruction (Fig. 7a), which utilised sites closer to the upper tree-line, implies good overall reconstruction performance and does not indicate the existence of any systematic weakening of reconstruction fidelity because of the lower elevation situation of the sampled sites.

Although limitations in the ability of regression-based approaches to accurately represent the full amplitude in reconstructions have previously been highlighted (Esper et al. 2005; von Storch et al. 2004), the strong calibration results should counteract such methodological limitations to some extent. However, it is worth considering that the NCAIRN reconstruction may under-represent the absolute magnitude of past temperature changes.

\section{Conclusion}

\subsection{Summary}

In this study, an 810-year summer temperature reconstruction, derived from temperature-sensitive Scots pine trees, is presented. A strong calibration with July-August mean temperatures was achieved, providing a good indication of summer temperature conditions in Scotland over much of the last millennium. Although uncertainty of the reconstruction increases back in time, it is possible to draw some conclusions about summer temperature in Scotland over the past $\sim 800$ years;

1. Within the context of reconstruction uncertainty, recent summertime warming is not significantly more pronounced than past reconstructed warm periods (e.g. around 1300 and 1500). The reliability of these earlier periods should, however, be viewed with caution.
2. The coldest protracted period occurred from the midsixteenth century until the early eighteenth century, coinciding with the LIA, with the 1690s representing the coldest decade. This is also corroborated by documentary and historical evidence. A shorter cold period was also observed before $~ 1270$ but uncertainty is rather large for this period.

3. Reconstruction of individual extreme cold years showed good agreement with instrumental observations and historical accounts (e.g. 1698, 1782 and 1799). However, the agreement of anomalously warm summer conditions with historical observations is poorer, likely reflecting an under-representation of warm summer extremes in historical documentation and a possible recruitment-related inflation bias of reconstructed years around 1300 in the TR record itself.

4. Comparing the new Scotland reconstruction with other UK and European temperature records reveals some similarities such as the generally colder LIA conditions and late twentieth/early twenty-first century warming. However, differences are also observed predominantly related to the distance between locations and expected spatial decay in agreement between temperature records, but also due to additional uncertainties such as different target seasons, detrending methods and the type of records or proxies used.

5. Superposed Epoch Analysis revealed a significant cooling response of about $0.3^{\circ} \mathrm{C}$ to volcanic eruptions in the NCAIRN reconstruction in the first post-event year, which is consistent with other examined European temperature records. On the whole there is a diminished response in NCAIRN relative to the other European records. This may be related to Scotland's maritime climate with the caveat that uncertainties exist in eruption timing and the spatial influence of sulphate aerosols.

6. Reconstructed extreme warm (cold) summer temperatures in the NCAIRN record coincide with high (low) pressure anomalies centred over the North Sea related to the positive (negative) phase of the summer NAO. The atmospheric circulation appears to have a greater influence on extreme cold summers than major volcanic events.

\subsection{Further research}

While the current NCAIRN reconstruction spans $\sim 800$ years, several other radiocarbon dated floating chronologies indicate multiple clusters of subfossil material within the Common Era and even earlier with the oldest lake preserved subfossil samples dating back $8000 \mathrm{cal} \mathrm{yr}$ BP (Wilson et al. 2012). This demonstrates the prospect 
of developing an even longer (perhaps at least 2000 year) reconstruction. The inclusion of additional TR data within the span covered by the current reconstruction would be of value, particularly before the $1530 \mathrm{~s}$, as this would lead to an improved expression of the climatic signal with overall signal strength improvement and reduced reconstruction uncertainty.

Extending the reconstruction (both in terms of temporal extent and replication) will be possible by increasing the availability of samples through the identification of additional suitable locations in other areas within or outside of the Cairngorms and sampling lake-preserved subfossil material from other parts of the Highlands. Promising new sites with lakes containing subfossil material have already been discovered as part of the ongoing Scottish Pine Project (http://www.st-andrews.ac.uk/ rjsw/ScottishPine/). Further extension will also be achieved by the addition of RW and BI data from existing undated subfossil samples (already collected and measured) as the chronology is extended back in time. The long Scottish chronology represents a valuable new resource which will also make it easier to identify and date samples from historical buildings and structures built with pine of Scottish origin within the last millennium and, therefore, the inclusion of dated series from historical and archaeological sources will assist with the further expansion of the long chronology.

Ongoing measurement of MXD on living and subfossil samples will lead to the development of an independent parameter reconstruction of past summer temperature allowing mutual validation between the current RW/BI version and a planned MXD reconstruction, and will provide further insight into late Holocene temperature variability in Scotland. These new data will lead to further advanced and detailed investigations with the aim to infer and understand mechanisms of past climate dynamics in NW Europe and the northeast Atlantic sector. In particular, the new NCAIRN record will be used to develop a reconstruction, and a more detailed understanding over much of the last millennium, of the Summer North Atlantic Oscillation (Folland et al. 2009; Linderholm et al. 2009) which is an important determinant of summer weather conditions particularly in northern Europe. The inclusion of NCAIRN in a recent TR based reconstruction update of northern hemisphere temperatures by the Northern Hemisphere TreeRing Network Development consortium (N-TREND - Wilson et al. 2016) further indicates the importance and utility of NCAIRN as a record that is helping to reveal the history of temperature variability before the availability of instrumental records in the northern hemisphere as well as NW Europe.

Acknowledgements We thank The Carnegie Trust for the Universities of Scotland for providing funding for Miloš Rydval's PhD. The
Scottish pine network expansion has been an ongoing task since 2007 and funding must be acknowledged to the following projects: EU project 'Millennium' (017008-2), Leverhulme Trust project 'RELiC: Reconstructing 8000 years of Environmental and Landscape change in the Cairngorms (F/00 268/BG)' and the NERC project 'SCOT2K: Reconstructing 2000 years of Scottish climate from tree rings (NE/ K003097/1)'. We also thank Keith Briffa and Michael Singer for comments on an early draft of this paper, and Rider University for a faculty research fellowship that supported Daniel Druckenbrod.

Open Access This article is distributed under the terms of the Creative Commons Attribution 4.0 International License (http:// creativecommons.org/licenses/by/4.0/), which permits unrestricted use, distribution, and reproduction in any medium, provided you give appropriate credit to the original author(s) and the source, provide a link to the Creative Commons license, and indicate if changes were made.

\section{References}

Adams JB, Mann ME, Ammann CM (2003) Proxy evidence for an El Nino-like response to volcanic forcing. Nature 426:274-278

Anchukaitis KJ, Breitenmoser P, Briffa KR, Buchwal A, Büntgen U, Cook ER, D'Arrigo RD, Esper J, Evans MN, Frank D et al (2012) Tree rings and volcanic cooling. Nat Geosci 5:836-837

Anchukaitis KJ, D’Arrigo RD, Andreu-Hayles L, Frank D, Verstege A, Curtis A, Buckley BM, Jacoby GC, Cook ER (2013) Treering-reconstructed summer temperatures from Northwestern North America during the Last Nine Centuries*. J Clim 26:3001-3012

Björklund JA, Gunnarson BE, Seftigen K, Esper J, Linderholm HW (2014a) Blue intensity and density from northern Fennoscandian tree rings, exploring the potential to improve summer temperature reconstructions with earlywood information. Clim Past $10: 877-885$

Björklund J, Gunnarson BE, Seftigen K, Zhang P, Linderholm HW (2014b) Using adjusted blue intensity data to attain high-quality summer temperature information: a case study from Central Scandinavia. Holocene 25:547-556

Blarquez O, Carcaillet C (2010) Fire, fuel composition and resilience threshold in subalpine ecosystem. PLoS One 5:e12480. doi:10.1371/journal.pone.0012480

Briffa K, Melvin T (2011) A closer look at regional curve standardization of tree-ring records: justification of the need, a warning of some pitfalls, and suggested improvements in its application. In: Hughes MK, Swetnam TW, Diaz HF (eds) Dendroclimatology: progress and prospects. Springer, Dordrecht, pp 113-145

Briffa KR, Bartholin TS, Eckstein D, Jones PD, Karlén W, Schweingruber FH, Zetterberg P (1990) A 1400-year tree-ring record of summer temperatures in Fennoscandia. Nature 346:434-439

Briffa KR, Jones PD, Bartholin TS, Eckstein D, Schweingruber FH, Karlen W, Zetterberg P, Eronen M (1992) Fennoscandian summers from $\mathrm{AD}$ 500: temperature changes on short and long timescales. Clim Dyn 7:111-119

Briffa KR, Osborn TJ, Schweingruber FH, Harris IC, Jones PD, Shiyatov SG, Vaganov EA (2001) Low-frequency temperature variations from a northern tree ring density network. J Geophys Res Atmos 106:2929-2941

Briffa KR, Osborn TJ, Schweingruber FH, Jones PD, Shiyatov SG, Vaganov EA (2002) Tree-ring width and density data around the Northern Hemisphere: part 2, spatio-temporal variability and associated climate patterns. Holocene 12:759-789 
Büntgen U, Hellmann L (2014) The Little Ice Age in scientific perspective: cold spells and caveats. J Interdiscip Hist 44:353-368

Büntgen U, Esper J, Frank DC, Nicolussi K, Schmidhalter M (2005) A 1052-year tree-ring proxy for Alpine summer temperatures. Clim Dyn 25:141-153

Büntgen U, Frank DC, Nievergelt D, Esper J (2006) Summer temperature variations in the European Alps, AD 755-2004. J Clim 19:5606-5623

Büntgen U, Kyncl T, Ginzler C, Jacks DS, Esper J, Tegel W, Heussner K-U, Kyncl J (2013) Filling the Eastern European gap in millennium-long temperature reconstructions. Proc Natl Acad Sci USA 110:1773-1778

Chapman PJ, Edwards AC, Cresser MS (2001) The nitrogen composition of streams in upland Scotland: some regional and seasonal differences. Sci Total Environ 265:65-83

Christiansen B, Ljungqvist FC (2011) Reconstruction of the extratropical $\mathrm{NH}$ mean temperature over the last millennium with a method that preserves low-frequency variability. J Clim 24:6013-6034

Compo GP, Whitaker JS, Sardeshmukh PD, Matsui N, Allan RJ, Yin $\mathrm{X}$, Gleason BE, Vose RS, Rutledge G, Bessemoulin $\mathrm{P}$ et al (2011) The Twentieth Century Reanalysis Project. Q J R Meteorol Soc 137:1-28

Cook ER, Peters K (1997) Calculating unbiased tree-ring indices for the study of climatic and environmental change. Holocene 7:361-370

Cook ER, Briffa KR, Meko DM, Graybill DA, Funkhouser G (1995) The 'segment length curse' in long tree-ring chronology development for palaeoclimatic studies. Holocene 5:229-237

Cook ER, Esper J, D’Arrigo RD (2004) Extra-tropical Northern Hemisphere land temperature variability over the past 1000 years. Quat Sci Rev 23: 2063-2074

Crone A, Mills CM (2002) Seeing the wood and the trees: dendrochronological studies in Scotland. Antiquity 76:788-794

D'Arrigo R, Wilson R, Jacoby G (2006) On the long -term context for late twentieth century warming. J Geophys Res Atmos 111:D03103

D’Arrigo R, Wilson R, Anchukaitis KJ (2013) Volcanic cooling signal in tree ring temperature records for the past millennium. J Geophys Res Atmos 118:9000-9010

Dawson AGD (2009) So foul and fair a day: a history of Scotland's weather and climate. Birlinn, Edinburgh

Dobrovolný P, Moberg A, Brázdil R, Pfister C, Glaser R, Wilson R, van Engelen A, Liman ó wka D, Kiss A, Hal íčkováM et al (2010) Monthly, seasonal and annual temperature reconstructions for Central Europe derived from documentary evidence and instrumental records since AD 1500. Clim Change 101:69107. doi:10.1029/2005JD006352

Druckenbrod DL (2005) Dendroecological reconstructions of forest disturbance history using time-series analysis with intervention detection. Can J Forest Res 35:868-876

Druckenbrod DL, Pederson N, Rentch J, Cook ER (2013) A comparison of times series approaches for dendroecological reconstructions of past canopy disturbance events. Forest Ecol Manag 302:23-33

Düthorn E, Holzkämper S, Timonen M, Esper J (2013) Influence of micro-site conditions on tree-ring climate signals and trends in central and northern Sweden. Trees 27:1395-1404

Düthorn E, Schneider L, Konter O, Schön P, Timonen M, Esper $J$ (2015) On the hidden significance of differing microsites on tree-ring based climate reconstructions. Silva Fenn. doi: $10.14214 /$ sf. 1220

Esper J, Cook ER, Schweingruber FH (2002) Low-frequency signals in long tree-ring chronologies for reconstructing past temperature variability. Science 295:2250-2253
Esper J, Frank DC, Wilson RJ, Briffa KR (2005) Effect of scaling and regression on reconstructed temperature amplitude for the past millennium. Geophys Res Lett 32:L07711. doi:10.1029/200 4GL021236

Esper J, Frank DC, Luterbacher J (2007) On selected issues and challenges in dendroclimatology. In: Kienast F, Wildi O, Ghosh S (eds) A changing world: challenges for landscape research. Springer, The Netherlands, pp 113-132

Esper J, Frank DC, Timonen M, Zorita E, Wilson RJS, Luterbacher J, Holzkämper S, Fischer N, Wagner S, Nievergelt D, Verstege A, Büntgen U (2012) Orbital forcing of tree-ring data. Nat Clim Change 2:862-866

Esper J, Schneider L, Krusic PJ, Luterbacher J, Büntgen U, Timonen M, Sirocko F, Zorita E (2013) European summer temperature response to annually dated volcanic eruptions over the past nine centuries. Bull Volcanol 75: 1-14

Esper J, Düthorn E, Krusic PJ, Timonen M, Buentgen U (2014) Northern European summer temperature variations over the Common Era from integrated tree-ring density records. J Quat Sci 29:487-494

Folland CK, Knight J, Linderholm HW, Fereday D, Ineson S, Hurrell JW (2009) The summer North Atlantic Oscillation: past, present, and future. J Clim 22:1082-1103

Frank D, Büntgen U, Böhm R, Maugeri M, Esper J (2007) Warmer early instrumental measurements versus colder reconstructed temperatures: shooting at a moving target. Quat Sci Rev 26: $3298-3310$

Fritts HC (1976) Tree rings and climate. Academic Press, London

Gao C, Robock A, Ammann C (2008) Volcanic forcing of climate over the past 1500 years: an improved ice core-based index for climate models. J Geophys Res Atmos 113:D23111. doi:10.102 9/2008JD010239

Grissino-Mayer HD (2001) Research report evaluating crossdating accuracy: a manual and tutorial for the computer program COFECHA. Tree Ring Res 57:205-221

Grudd H (2008) Torneträsk tree-ring width and density AD 5002004: a test of climatic sensitivity and a new 1500-year reconstruction of north Fennoscandian summers. Clim Dyn $31: 843-857$

Grudd H, Briffa KR, Karlén W, Bartholin TS, Jones PD, Kromer B (2002) A 7400-year tree-ring chronology in northern Swedish Lapland: natural climatic variability expressed on annual to millennial timescales. Holocene 12:657-665

Gunnarson BE, Linderholm HW, Moberg A (2011) Improving a treering reconstruction from west-central Scandinavia: 900 years of warm-season temperatures. Clim Dyn 36:97-108

Harris I, Jones PD, Osborn TJ, Lister DH (2014) Updated high-resolution grids of monthly climatic observations-the CRU TS3.10 Dataset. Int J Climatol 34:623-642

Hegerl GC, Crowley TJ, Allen M, Hyde WT, Pollack HN, Smerdon J, Zorita E (2007) Detection of human influence on a new, validated 1500-year temperature reconstruction. J Clim 20:650-666

Helama S, Lindholm M, Timonen M, Meriläinen J, Eronen M (2002) The supra-long Scots pine tree-ring record for Finnish Lapland: part 2 , interannual to centennial variability in summer temperatures for 7500 years. Holocene 12:681-687

Helama S, Vartiainen M, Holopainen J, Mäkelä HM, Kolström T, Meriläinen J (2014) A palaeotemperature record for the Finnish Lakeland based on microdensitometric variations in tree rings. Geochronometria 41:265-277

Hughes MK, Schweingruber FH, Cartwright D, Kelly PM (1984) July-August temperature at Edinburgh between 1721 and 1975 from tree-ring density and width data. Nature 308:341-344

IPCC, Stocker TF, Qin D, Plattner GK, Tignor MMB, Allen SK, Boschung J, Nauels A, Xia Y, Bex V, Midgley PM (eds) (2014) Climate change 2013: the physical science basis: 
Working Group I Contribution to the Fifth Assessment Report of the International Panel on Climate Change. Cambridge University Press, Cambridge

Jirikowic JL, Damon PE (1994) The medieval solar activity maximum. Clim Change 26:309-316

Jones PD, Lister D (2004) The development of monthly temperature series for Scotland and Northern Ireland. Int J Climatol 24:569-590

Jones PD, Briffa KR, Barnett TP, Tett SFB (1998) High-resolution palaeoclimatic records for the last millennium: interpretation, integration and comparison with General Circulation Model control-run temperatures. Holocene 8:455-471

Jones PD, Briffa KR, Osborn TJ, Lough JM, van Ommen TD, Vinther BM, Luterbacher J, Wahl ER, Zwiers FW, Mann ME, Schmidt GA et al (2009) High-resolution palaeoclimatology of the last millennium: a review of current status and future prospects. Holocene 19:3-49

Lamb HH (1964) Trees and climatic history in Scotland. Q J R Meteorol Soc 90: 382-394

Lamb HH (1965) The early medieval warm epoch and its sequel. Palaeogeogr Palaeocl 1:13-37

Larsson L (2014) CooRecorder and Cdendro programs of the CooRecorder/Cdendro package version 7.7. http://www.cybis. se/forfun/dendro. Accessed 3 Jan 2014

Liñán ID, Büntgen U, González-Rouco F, Zorita E, Montávez JP, Gómez-Navarro JJ, Brunet M, Heinrich I, Gutiérrez E (2012) Estimating 750 years of temperature variations and uncertainties in the Pyrenees by tree-ring reconstructions and climate simulations. Clim Past 8:919-933

Linderholm HW, Gunnarson BE (2005) Summer temperature variability in central Scandinavia during the last 3600 years. Geogr Ann A 87: 231-241

Linderholm HW, Folland CK, Walther A (2009) A multicentury perspective on the summer North Atlantic Oscillation (SNAO) and drought in the eastern Atlantic Region. J Quat Sci 24:415-425

Linderholm HW, Zhang P, Gunnarson BE, Björklund J, Farahat E, Fuentes M, Rocha E, Salo R, Seftigen K, Stridbeck P, Liu Y (2014) Growth dynamics of tree-line and lake-shore Scots pine (Pinus sylvestris L.) in the central Scandinavian Mountains during the Medieval Climate Anomaly and the early Little Ice Age. Front Ecol Evol. doi:10.1007/s00468-015-1205-4

Linderholm HW, Björklund J, Seftigen K, Gunnarson BE, Fuentes M (2015) Fennoscandia revisited: a spatially improved tree-ring reconstruction of summer temperatures for the last 900 years. Clim Dyn 45:933-947

Luterbacher J, Xoplaki E, Dietrich D, Rickli R, Jacobeit J, Beck C, Gyalistras D, Schmutz C, Wanner H (2002) Reconstruction of sea level pressure fields over the eastern north Atlantic and Europe back to 1500 . Clim Dyn 18:545-561

Luterbacher J, Dietrich D, Xoplaki E, Grosjean M, Wanner H (2004) European seasonal and annual temperature variability, trends, and extremes since 1500. Science 303:1499-1503

Manley G (1974) Central England temperatures: monthly means 1659 to 1973. Q J R Meteorol Soc 100:389-405

Mann ME, Jones PD (2003) Global surface temperatures over the past two millennia. Geophys Res Lett. doi:10.1029/2003GL017814

Mann ME, Zhang Z, Hughes MK, Bradley RS, Miller SK, Rutherford S, Ni F (2008) Proxy-based reconstructions of hemispheric and global surface temperature variations over the past two millennia. Proc Natl Acad Sci USA 105:13252-13257

Mann ME, Fuentes JD, Rutherford S (2012) Underestimation of volcanic cooling in tree-ring-based reconstructions of hemispheric temperatures. Nat Geosci 5:202-205

Matskovsky VV, Helama S (2014) Testing long-term summer temperature reconstruction based on maximum density chronologies obtained by reanalysis of tree-ring data sets from northernmost Sweden and Finland. Clim Past 10:1473-1487

Matthews JA, Briffa KR (2005) The 'Little Ice Age': re-evaluation of an evolving concept. Geogr Ann A 87:17-36

McCarroll D, Pettigrew E, Luckman A, Guibal F, Edouard J-L (2002) Blue reflectance provides a surrogate for latewood density of high-latitude pine tree rings. Arct Antarct Alp Res 34:450-453

McCarroll D, Loader NJ, Jalkanen R, Gagen MH, Grudd H, Gunnarson BE, Kirchhefer AJ, Friedrich M, Linderholm HW, Lindholm M et al (2013) A 1200-year multiproxy record of tree growth and summer temperature at the northern pine forest limit of Europe. Holocene 23:471-484

McCarroll D, Young GH, Loader NJ (2015) Measuring the skill of variance-scaled climate reconstructions and a test for the capture of extremes. Holocene 25:618-626

Melvin TM, Briffa KR (2008) A "signal-free" approach to dendroclimatic standardisation. Dendrochronologia 26:71-86

Miller GR, Cummins RP (1982) Regeneration of Scots pine Pinus sylvestris at a natural tree-line in the Cairngorm Mountains, Scotland. Ecography 5:27-34

Moberg A, Alexandersson H, Bergström H, Jones PD (2003) Were southern Swedish summer temperatures before 1860 as warm as measured? Int J Climatol 23:1495-1521

Moberg A, Sonechkin DM, Holmgren K, Datsenko NM, Karlén W (2005) Highly variable Northern Hemisphere temperatures reconstructed from low-and high-resolution proxy data. Nature 433:613-617

Neukom R, Gergis J, Karoly DJ, Wanner H, Curran M, Elbert J, Gonz ález-Rouco F, Linsley BK, Moy AD, Mundo I et al (2014) Inter-hemispheric temperature variability over the past millennium. Nat Clim Change 4:362-367

Oosthoek J (2013) Conquering the highlands: a history of the afforestation of the Scottish uplands. ANU E Press, Canberra

Osborn TJ, Briffa KR (2006) The spatial extent of 20th-century warmth in the context of the past 1200 years. Science 311:841-844

Osborn TJ, Briffa KR, Jones PD (1997) Adjusting variance for sample size in tree-ring chronologies and other regional mean timeseries. Dendrochronologia 15:89-99

Parker D, Horton B (2005) Uncertainties in central England temperature 1878-2003 and some improvements to the maximum and minimum series. Int J Climatol 25:1173-1188

Parker DE, Legg TP, Folland CK (1992) A new daily central England temperature series, 1772-1991. Int J Climatol 12:317-342

Plummer CT, Curran MAJ, Ommen TDV, Rasmussen SO, Moy AD, Vance TR, Clausen HB, Vinther BM, Mayewski PA (2012) An independently dated 2000-year volcanic record from Law Dome, East Antarctica, including a new perspective on the dating of the 1450s CE eruption of Kuwae, Vanuatu. Clim Past 8:1929-1940

Popa I, Kern Z (2009) Long-term summer temperature reconstruction inferred from tree-ring records from the Eastern Carpathians. Clim Dyn 32:1107-1117

Rydval M, Larsson L-Å, McGlynn L, Gunnarson BE, Loader NJ, Young GH, Wilson R (2014) Blue intensity for dendroclimatology: should we have the blues? Experiments from Scotland. Dendrochronologia 32:191-204

Rydval M, Druckenbrod D, Anchukaitis KJ, Wilson R (2016a) Detection and removal of disturbance trends in tree-ring series for dendroclimatology. Can J Forest Res 46:387-401

Rydval M, Gunnarson BE, Loader NJ, Cook ER, Druckenbrod DL, Wilson R (2016b) Spatial reconstruction of Scottish summer temperatures from tree rings. Int J Climatol. doi:10.1002/ joc. 4796

Schneider L, Smerdon J, Büntgen U, Wilson R, Myglan V, Kirdyanov A, Esper J (2015) Revising midlatitude summer temperatures 
back to A.D. 600 based on a wood density network. Geophys Res Lett 42:4556-4562

Sigl M, Winstrup M, McConnell JR, Welten KC, Plunkett G, Ludlow F, Büntgen U, Caffee M, Chellman N, Dahl-Jensen D, Fischer H, Kipfstuhl S, Kostick C, Maselli OJ, Mekhaldi F, Mulvaney R, Muscheler R, Pasteris DR, Pilcher JR, Salzer M, Schüpbach S, Steffensen JP, Vinther BM, Woodruff TE (2015) Timing and climate forcing of volcanic eruptions for the past 2500 years. Nature 523:543-549

Smout TC, MacDonald AR, Watson F (2005) A history of the native woodlands of Scotland, 1500-1920. Edinburgh University Press, Edinburgh

Stoffel M, Khodri M, Corona C, Guillet S, Poulain V, Bekki S, Guiot J, Luckman B, Oppenheimer C, Lebas N, Beniston M, MassonDelmotte V (2015) Estimates of volcanic-induced cooling in the Northern Hemisphere over the past 1500 years. Nat Geosci 8:784-788

Usoskin IG, Solanki SK, Kovaltsov GA (2007) Grand minima and maxima of solar activity: new observational constraints. Astron Astrophys 471: 301-309

von Storch H, Zorita E, Jones JM, Dimitriev Y, González-Rouco F, Tett SF (2004) Reconstructing past climate from noisy data. Science 306:679-682

Wagner S, Zorita E (2005) The influence of volcanic, solar and $\mathrm{CO}_{2}$ forcing on the temperatures in the Dalton Minimum (17901830): a model study. Clim Dyn 25:205-218
Walton K (1952) Climate and famines in north east Scotland. Scot Geogr Mag 68:13-21

Warren WG (1980) On removing the growth trend from dendrochronological data. Tree Ring Bull 40:35-44

Wigley TM, Briffa KR, Jones PD (1984) On the average value of correlated time series, with applications in dendroclimatology and hydrometeorology. J Clim Appl Meteorol 23:201-213

Wilson R, Frank D, Topham J, Nicolussi K, Esper J (2005) Spatial reconstruction of summer temperatures in Central Europe for the last 500 years using annually resolved proxy records: problems and opportunities. Boreas 34:490-497

Wilson R, Loader NJ, Rydval M, Patton H, Frith A, Mills CM, Crone A, Edwards C, Larsson L, Gunnarson BE (2012) Reconstructing Holocene climate from tree rings: the potential for a long chronology from the Scottish Highlands. Holocene 22:3-11

Wilson R, Anchukaitis K, Briffa KR, Büntgen U, Cook E, D’Arrigo R, Davi N, Esper J, Frank D, Gunnarson B, Hegerl G, Helama S, Klesse S, Krusic PJ, Linderholm HW, Myglan V, Osborn TJ, Rydval M, Schneider L, Schurer A, Wiles G, Zhang P, Zorita E (2016) Last millennium northern hemisphere summer temperatures from tree rings: part I: the long term context. Quat Sci Rev 134:1-18

Zhang P, Linderholm HW, Gunnarson BE, Björklund J, Chen D (2015) 1200 years of warm-season temperature variability in central Fennoscandia inferred from tree-ring density. Clim Past Discuss 11:489-519 